ANUARIO DE Estudios MEDIEVALES 46/2, julio-diciembre de 2016, pp. 819-858

ISSN 0066-5061

doi:10.3989/aem.2016.46.2.08

\title{
LA PRODUCCIÓN DE CARBÓN EN EL REINO DE CÓRDOBA A FINES DE LA EDAD MEDIA: UN EJEMPLO DE APROVECHAMIENTO DEL MONTE MEDITERRÁNEO ${ }^{1}$
}

\author{
THE WOOD CHARCOAL PRODUCTION IN THE KINGDOM \\ OF CÓRDOBA AT THE END OF THE MIDDLE AGES: \\ AN EXAMPLE OF THE EXPLOITATION \\ OF THE MEDITERRANEAN MOUNTAIN
}

JAVIER LÓPEZ RIDER

Universidad de Córdoba

\begin{abstract}
Resumen: El objeto de este estudio es indagar y explicar qué supone la práctica del carboneo y el carbón en el reino de Córdoba durante el periodo bajomedieval. Ante la carencia de estudios antracológi$\cos$, las fuentes documentales plasman la tipología de carbones existentes, cómo se obtenía esta materia prima, a qué usos se destinaba, cómo era transportado hasta la ciudad, y en último lugar, su comercialización. Gracias a esta información se puede comprender el significado que tenía el carboneo para nuestros antepasados, pues nos han dejado un legado carbonífero que seguimos utilizando en la actualidad.
\end{abstract}

Palabras clave: Córdoba; economía; paisaje; carbón; monte; Baja Edad Media; comercio.

\begin{abstract}
The aim of this research is to investigate and explain, the practice of wood charcoal production in the kingdom of Córdoba during the Middle Ages Period. In the absence of anthracological studies; the documentary sources reveal the typology of existing charcoals, how this raw material was obtained, which its uses were, how it was transported to the city and in wich ways it was commercialized. Thanks to all this information we come to understand the importance of wood charcoal production for our ancestors, who have left us a carboniferous legacy we still use.
\end{abstract}

Keywords: Córdoba; economy; landscape; charcoal; mount; Late Middle Ages; trade.

${ }^{1}$ Este trabajo ha sido realizado en el marco del proyecto HAR2015-67619P Tecnología y conocimiento en la Península Ibérica (siglos XIII-XVI), financiado por el Ministerio de Economía y Competitividad, parcialmente con fondos FEDER.

Abreviaturas utilizadas: AGS = Archivo General de Simancas; $\mathrm{AHPCO}=$ Archivo Histórico Provincial de Córdoba; $\mathrm{AMCO}=$ Archivo Municipal de Córdoba; $\mathrm{LAC}=$ Libro de Acta Capitular; Mrs. = Maravedíes; $\mathrm{OM}=$ Ordenanzas Municipales; $\mathrm{PNCO}=$ Sección de Protocolos Notariales de Córdoba; RGS = Registro General del Sello. 


\section{SUMARIO}

1. Introducción.- 2. Legislación y protección del monte ante el carboneo.- 2.1. Tipos de carbones.- 2.2. Fabricación del carbón vegetal.- 2.3. El transporte.- 2.4 Comercialización.- 3. Conclusiones.- 4. Bibliografía citada.

\section{INTRODUCCIÓN}

Cada vez son mayores los estudios dedicados al ámbito de la historia natural, forestal y/o medioambiental, investigados desde una visión económica y rural pero también con un alto gradiente ecológico. Así lo demuestran las diversas reuniones científicas celebradas hasta el momento que han ido despertando nuevos enfoques acerca de esta temática. En 1999 surgió la I reunión del grupo de trabajo "Historia Forestal", donde se logró la asistencia de muchos especialistas de diversas disciplinas teniendo todos ellos un único objetivo, hablar del hombre y del medio ambiente ${ }^{2}$. Siguiendo un orden cronológico, en el año 2001 tuvo lugar otro congreso celebrado en Cáceres, donde comenzó a cobrar mayor importancia un concepto muy llamativo denominado "ecohistoria"3. Gracias a éste, se han tenido en consideración los fuertes impactos y transformaciones que ha ido sufrido el medio ambiente por la acción del hombre en los siglos bajomedievales y modernos, herencia que llega hasta nuestros días. Aquí cobra sentido la explicación de Segura Graiño acerca del interés suscitado por las relaciones existentes entre las personas y el espacio, lo que ha provocado el surgimiento del pensamiento ecológico, apareciendo de este modo la Ecología con importantes connotaciones económicas y sociales ${ }^{4}$.

Con el tiempo, surgieron muchas otras reuniones con el objetivo de indagar en la historia natural y medioambiental; por ejemplo, se celebraron

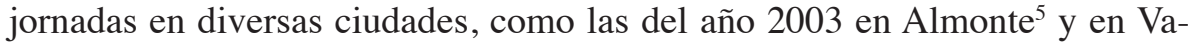
lladolid, volviéndose a aglutinar, en ésta última, el ya citado grupo de trabajo Historia Forestal ${ }^{6}$, o aquellas de apenas hace unos años realizadas en Cádiz ${ }^{7}$. No cabe duda de que los congresos mencionados hasta el momento son un espejo de la preocupación de la sociedad -cada vez mayor- por los problemas medioambientales y las nefastas consecuencias acerca del aumento poblacio-

${ }^{2}$ Manuel 1999.

${ }^{3}$ Clemente 2001. Véase igualmente González, Martínez 1993.

${ }^{4}$ Segura 2009, p. 377

${ }^{5}$ Pérez-Embid 2002.

${ }^{6}$ Guerra, et al. 2003.

${ }^{7}$ Martín 2011. 
nal que acontece. Por este motivo, cada vez son más los historiadores que se interesan por las relaciones entre el ser humano y su entorno natural a lo largo de la historia.

La transformación del bosque por los hombres se ocasiona por dos factores: la estructuración del espacio y la explotación de los recursos disponibles ${ }^{8}$. En el segundo de los motivos, se comprende lo señalado por Elisa Carolina al explicar que el bosque proporcionaba infinidad de recursos: madera, leña, carbón, pastos para la ganadería, caza, frutos silvestres, miel, pesca, incluso como refugio para ladrones ${ }^{9}$. Para el caso concreto de Córdoba, existen diversos estudios que han profundizado en algunas de estas actividades ${ }^{10}$. Las siguientes páginas, se ceñirán exclusivamente a uno de los aprovechamientos del monte menos estudiado hasta el momento, como es la práctica del carboneo y el uso del carbón en el reino de Córdoba para el periodo bajomedieval.

\section{LEGISLACIÓN Y PROTECCIÓN DEL MONTE ANTE EL CARBONEO}

Como se ha comentado anteriormente, una de las causas de la transformación del bosque es la explotación del mismo ante la gran demanda que existía por parte del hombre medieval. Ya sea a través de la extracción de leña, la creación de tierras de cultivos o la quema para la obtención de pastos o carbón, el resultado es una fuerte degradación de la superficie cubierta del monte durante el medievo. De este modo, se puede comprender que las desforestaciones que existen en la actualidad son una herencia del pasado, pues tanto en Europa como en la Península Ibérica, ya desde la Edad Media, se implantaron todo tipo de ordenanzas protectoras de las zonas boscosas con la finalidad de evitar su destrucción. El carbón ha sido uno de los carburantes más utilizados en la historia, sobre todo para actividades domésticas y metalúrgicas ${ }^{11}$. Por ejemplo, en los hogares, como picón de braseros para combatir el frío, o el carbón de brezo, como fuente de energía para alimentar las fraguas ${ }^{12}$.

Desde finales del siglo XIII y comienzos del siglo XIV, la práctica del carboneo provocó que la superficie ocupada por el bosque fuera disminuyendo de forma notable en la Península Ibérica. Esto motivó que los concejos tomasen estrictas medidas para evitar la desaparición de sus montes. Un as-

\footnotetext{
${ }^{8}$ Clément 2003, pp. 39-40.

${ }^{9}$ Santos 1986, p. 383 .

${ }^{10}$ Hidalgo 1998; Córdoba 1990a, vol. I, pp. 777-790; González 1975, p. 259; López 1989, p. 42; Pino 1996, pp. 89-118.

${ }^{11}$ Martín 2012, vol. II, p. 1562.

${ }^{12}$ Córdoba 1990b, pp. 223-225.
} 
pecto que no debería de extrañarnos puesto que, según la hipótesis de Segura Graiño, es posible que existiera una mentalidad más o menos ecológica ya desde el siglo XI en al-Andalus o a partir del siglo XIII en los reinos cristianos ${ }^{13}$. Probablemente esa nueva interpretación del hábitat forestal proceda del cambio de función atribuida al propio bosque. Como ya señaló Vincent Clément, aunque en toda la Europa medieval el bosque estuvo completamente relacionado con los sistemas fronterizos ${ }^{14}$, en la Península Ibérica, tras la victoria en la batalla de las Navas de Tolosa, dejó de ser una frontera natural y se transformó en un espacio de explotación económica en manos cristianas ${ }^{15}$. Anteriormente los musulmanes del califato cordobés consideraban al bosque como un espacio defensivo que protegía el territorio de al-Andalus, mientras que los cristianos lo percibían como tierras a conquistar y que se podrían aprovechar por los recursos que proporcionaban ${ }^{16}$. Hasta ese momento nadie pensaba en la necesidad de proteger la naturaleza, sino todo lo contrario, habría que defenderse de ella ante los posibles peligros que ocasionaba ${ }^{17}$.

Una vez conseguidas esas tierras por el bando cristiano, y con el transcurrir del tiempo, la población comenzó a incrementarse, lo que condujo a la necesidad de salvaguardar el bosque ante la demanda tan fuerte que se acontecía sobre las diversas materias primas existentes ${ }^{18}$, surgiendo así una incipiente mentalidad ecológica.

Cuando el hombre medieval llevaba a cabo la actividad carbonera, al mismo tiempo, realizaba otras explotaciones que eran bastantes perjudiciales para el propio monte. A continuación, se va a analizar la creación -por parte de las ciudades- de una legislación para hacer frente a estas acciones tan destructivas. En primer lugar, hay que centrarse en las talas abusivas que se ejercieron sobre los árboles. Estas eran tan frecuentes que los concejos aplicaron todo tipo de medidas para evitarlas, de lo contrario, podrían exterminar algunas de las especies arbóreas más consumidas. No son escasos los testimonios que se conocen de ciudades que emitieron ordenanzas específicas para regular el desmoche de los montes. Algunas de ellas, se dictaron en el siglo XIV con intención de evitar situaciones con unas consecuencias tan nefastas como la acontecida en la zona de Couserans, donde se sufrió una fuerte desforestación sin paliativos desde finales del siglo XIV hasta principios de la Edad

\footnotetext{
${ }^{13}$ Segura 2009, p. 378.

${ }^{14}$ Clément 1997, p. 329.

${ }^{15}$ Clément 2003, p. 58.

${ }^{16}$ Clément 1993, p. 113.

${ }^{17}$ Segura 2009, p. 382.

${ }^{18}$ Clemente 1999, p. 442.
} 
Moderna ${ }^{19}$. En la Península Ibérica, existen tempranos y diversos ejemplos sobre legislaciones acerca de esta explotación. Aquí se recogen dos casos, uno el de Orihuela, que en 1307 será cuando elaboren unas medidas protectoras mucho más estrictas hacia leñadores que talasen árboles sin permiso; teniendo como pena la pérdida del puño derecho ${ }^{20}$. El otro caso, es el de la zona norte peninsular (País Vasco, condado de Foix o Cataluña), donde a lo largo del siglo XIV se intenta establecer una legislación con numerosas prohibiciones. En las zonas centrales de la Península, como en Béjar o Piedrahita, si el leñador recogía más leña de la permitida por el concejo, la pena era de $24 \mathrm{mrs}$. a la primera vez, $100 \mathrm{mrs}$. a la segunda y 100 azotes a la tercera ${ }^{21}$.

Si se analizan las legislaciones que se desarrollaron, existen muchas semejanzas a lo largo de la geografía peninsular. Una muy común entre las diversas regiones españolas es aplicar la protección sobre una tipología de árbol determinada, que en la mayoría de las ocasiones, es la más explotada. Es el caso de los pinares de Sepúlveda y Cuéllar que eran protegidos ante las infracciones forestales, imponiendo guardas para que evitaran las talas de pinos verdes o ramas para hacer carbón, provocar fuegos de rozas o arrancar cortezas $^{22}$. El área extremeña, concretamente en Trujillo o Cáceres, las ordenanzas del monte ya existían para finales del siglo XV o principios del XVI, indicándonos también la sanción que se aplicaba según la clase de árbol que era cortado ${ }^{23}$. En Plasencia, existía un estricto control sobre la poda del monte, será Pedro de Estúñiga quien prohíba cortar cualquier rama para 1463, solo se permitía el ramoneo ${ }^{24}$.

Del mismo modo en Andalucía, aparecen testimoniadas qué especies gozaban de una mayor protección. En Jaén se penaba con 60 mrs. el corte de leña en las dehesas del Carrascal y la Torre Gil de Olid, en cambio si se cortaban de lentisco, coscoja, retamas, tarajes o bardas debían pechar $10 \mathrm{mrs}$. cada vez que lo hicieran. Los boyerizos estaban exentos de pena ${ }^{25}$. En la sierra de Aracena y Aroche los concejos aplicaron normativas para el uso descontrolado del bosque, a través de sus respectivas ordenanzas penaban el corte por el pie sobre el alcornoque o la encina, limitaban la tala de los árboles para el disfrute de los bueyes de arada o la saca del corcho y el

\footnotetext{
${ }^{19}$ Verna 2002, pp. 345-353.

${ }^{20}$ Furió 2001, p. 101.

${ }^{21}$ Santos 1986, p. 388.

${ }^{22}$ Clément 2003, p. 59.

${ }^{23}$ Clemente 1999, pp. 443-445. En 1460, cortar un castaño era penado con 2.000 mrs., un pino $600 \mathrm{mrs}$. y una encina $400 \mathrm{mrs}$.

${ }^{24}$ Ibidem, p. 444.

${ }^{25}$ Rodríguez 1978, p. 298.
} 
aprovechamiento de ciertas dehesas; cuyas penas eran dobladas a $1.000 \mathrm{mrs}$. si lo realizaban sin licencia ${ }^{26}$. A pesar de aplicar estas medidas, en la sierra de Aracena los habitantes seguían disfrutando de los montes, en concreto los denominados "Las Atarazanas" que estuvieron fuertemente explotados entre los años 1478 y 1481. Incluso la propia justicia denunciaba a los vecinos de las acciones tan destructivas que efectuaban, como por ejemplo e cortando los árboles e enzinas e otros árboles para fazer dellos carbón ${ }^{27}$. La costa granadina también sufrió una gran deforestación por motivo de la fabricación de azúcar ${ }^{28}$. Por su parte, el concejo de Córdoba impuso alguna que otra ordenanza acerca de la corta para diferentes años. Por ejemplo en 1492, se recoge la prohibición de llevar a cabo el desmoche de las encinas, indicando incluso al uso que muchas de ellas estaban destinadas: Al tiempo que señalades los dichos montes, se de orden como no se destruyan los encinares, de manera que quede en ellos enzinas para faser ruedas de carretas e vigas e las otras cosas nescesarias ${ }^{29}$.

Años antes, concretamente en 1435 ya existía otra ordenanza, donde se recogía tanto el corte como la quema, especificando varios árboles que eran objeto de explotación:

por otra razón alguna cortaren o quemaren enzinas o alcornoques o guadaperos en sus heredades o en otra parte alguna en los nuestros montes, que por cada árbol destos que cortare o quemare, como dicho es, peche en pena el que lo fiziere cien mrs. para el concejo e doze mrs. para el mayordomo ${ }^{30}$.

En relación con esta última ordenanza cordobesa, se conecta una segunda actividad unida a la fabricación del carbón; cuyo nivel de peligrosidad es superior, se trata de la quema. Como ya es sabido, los carboneros solían originar incendios para conseguir su producto llegando a provocar unas consecuencias mucho más perniciosas que las talas de árboles analizadas anteriormente. Por ello, la denominada "quema" producía mayor inquietud entre las ciudades. Así lo demuestran las decisiones tomadas en las Cortes de Valladolid de 1351 sobre la imposición de severas medidas hacia ganaderos o carboneros, expresando una preocupación por la quema de montes que realizaban constantemente para obtener recursos como pastos o carbón. Al igual que ocurre con la legislación establecida para las podas de árboles, las medidas que se

\footnotetext{
${ }^{26}$ Pérez-Embid 1988, pp. 260-262.

${ }^{27}$ Pérez-Embid 2001, p. 462.

${ }^{28}$ Malpica 2001,p. 162.

${ }^{29}$ 1492.05.24, AGS, RGS, f. 556r-v.

${ }^{30}$ González 1975, p. 258.
} 
instauran para paliar los fuegos en el monte medieval, eran comunes en toda la Península Ibérica.

Para la región andaluza, el concejo cordobés no solo aplicó la pena ya citada para 1435, sino que contaba con otras sanciones. En primer lugar, cualquier carbonero que hiciera carbón cerca de un árbol y éste resultase quemado o chamuscado, sería llevado ante la justicia. El concejo llegó incluso a establecer los días que debían permanecer los pastores o señores sin entrar en las zonas que se hicieran quemados, ordenando que aquellos permanezcan sin meter los ganados desde el día que se realiza la quema hasta pasados treinta días ${ }^{31}$. En caso de que no se cumpliera, la pena consistía en pagar 100 mrs. para el concejo de Córdoba y $12 \mathrm{mrs}$. para los mayordomos. Del mismo modo era vetada la entrada a carboneros, en esta ordenanza se estipula que estos no sean osados de fazer carbón en quemado bajo la pena de $200 \mathrm{mrs}$. por cada vez que lo hiciesen, y $12 \mathrm{mrs}$. para el mayordomo ${ }^{32}$. No obstante, conforme avanza el siglo XV se endurece la penalización añadiendo que los carboneros pierdan el carbón que hubiesen hecho y 300 mrs. a pagar. El cabildo cordobés llegó incluso a ordenar que se respetaran los meses de verano a la hora de realizar fuegos; medida que actualmente se sigue manteniendo puesto que los meses de junio, julio, agosto y septiembre son proclives a numerosos incendios, que acompañados por las altas temperaturas alcanzadas, se vuelven incontrolables. El prohibir durante este marco temporal esos fuegos se justifica en la época estudiada porque vyenen muchos males e daños a panes e vyñas e huertas e olyvares e pastos e colmenares e a otras cosas ${ }^{33}$. La importancia que tenía esta última medida se deja entrever en el documento ya que las penas que se imponen son mucho más fuertes que las inicialmente vistas. Se sigue manteniendo el pago de los 12 mrs. para los mayordomos, pero además el culpable está obligado a correr con los gastos del daño que causara el fuego; aparte de aportar $600 \mathrm{mrs}$. para el concejo de la ciudad.

Al respecto, se conserva la ordenanza de 1495 que muestra no sólo los pleitos que sucedían, sino también el modo en que buscaban una solución para proteger el propio monte. El 6 de agosto de 1495 el concejo de la ciudad recibe ciertas quejas por parte de los colmeneros acerca de los fuegos que se efectuaban en los montes cercanos a sus colmenas. Según estos, los principales culpables son los carboneros que hacen carbón de breço $o^{34}$ y suplican al cabildo que mande que los carboneros no entren en los quemados a fazer carbón fasta tres años ${ }^{35}$. El concejo de Córdoba, decretó que se reunieran tanto

${ }^{31}$ Ibidem, p. 255.

${ }^{32}$ Ibidem, p. 256.

${ }^{33}$ Ibidem.

${ }^{34}$ AMCO, OM, Libro $1^{\circ}$, f. 248 v.

${ }^{35}$ Ibidem.

ANUARIO DE Estudios MEdievales, 46/2, julio-diciembre 2016, pp. 819-858 ISSN 0066-5061, doi:10.3989/aem.2016.46.2.08 
colmeneros como carboneros para acordar si era viable esta posibilidad de tres años de margen continuos, y el resultado fue un respaldo unánime para que se implantara ese tiempo so pena que cada vez que fueren tomados en los dichos quemados faziendo carbón paguen trezientos $m r s .{ }^{36}$. La normativa aplicada en Andalucía también se documenta en otras regiones peninsulares, por ejemplo en Cuéllar y Sepúlveda, donde sus ordenanzas mencionan que ningún vezino de las dichas villas e sus tierras no sean osados de hazer fuego ninguno en los dichos pinares comunes en los meses de julio, agosto e setiembre en rrededor de ningun pino ni pinos ${ }^{37}$.

Otra medida protectora emanada por las diferentes políticas municipales de las ciudades bajomedievales, era la de elegir lugares concretos para la explotación del monte, y por tanto, del carbón. Esta disposición se llevó a cabo porque la intensiva fabricación de este producto originaba grandes cambios químicos en el suelo, y si la producción del mismo era continua en un lugar concreto, el área podría quedar estéril ${ }^{38}$. Por este motivo, al igual que ocurre en la explotación de cultivos agrícolas, los concejos mandaban respetar durante un tiempo determinado los lugares de monte para que descansaran del aprovechamiento a que son sometidos constantemente, incluso llegan al extremo de explotar la sierra por diferentes áreas para que su aprovechamiento sea mucho más equitativo. Lo común era destinar ciertos momentos del año para llevar a cabo esta actividad. En tierras extremeñas, concretamente en Plasencia, eran los concejos quienes indicaban en qué lugares se permitía la realización de carbón, aunque los carboneros debían poseer su oportuna licencia para ello. En Andalucía ocurría lo mismo, por ejemplo en la villa de Alcalá de los Gazules, donde la explotación del carbón se realizaba en un espacio elegido para tal fin por el mayordomo del concejo ${ }^{39}$. Por su parte, el reino de Jaén a través de su ordenanza XIII, mandó hacer el carbón desde Pascua Florida hasta Todos los Santos en los Portichuelos de Ravera, y desde Todos los Santos hasta Pascua Florida, en la Mezquita ${ }^{40}$. En la ciudad de Córdoba y para el año de 1492, el concejo señaló anualmente una zona diferente para la realización del carbón:

para que no se destruyan los montes de la ciudad, que ésta señale cada año un lugar limitado donde se corte la leña que fuere

${ }^{36}$ Ibidem, f. 249r.

${ }^{37}$ Calonge 2003, pp. 106.

${ }^{38}$ Almagro 2012, pp. 257-258.

${ }^{39}$ Martín 2012, p. 1564.

${ }^{40}$ Porras 1993, p. 137. 
menester para hacer carbón, y no se pueda hacer en otra parte alguna; y que en un año señale los montes en una parte y otro año en otra diferente, de manera que el daño se reparta por toda la tierra de la ciudad ${ }^{41}$.

Sin embargo, no siempre se cumplían esas restricciones geográficas ni tampoco los espacios temporales marcados, por eso algunas ciudades contrataban a guardas para que vigilaran y penaran cualquier infracción que se cometiera. En Castellón se llegaron a imponer estos guardas forestales con el fin de evitar que los habitantes siguieran consumiendo los recursos del bosque irracionalmente ${ }^{42}$. Como toda la protección impuesta a la madera afectaba a la explotación vegetal, que era el principal objetivo de los carboneros durante la época de invierno, estos guardas forestales o caballeros de la sierra, llevaban a cabo una vigilancia y un control muy estrictos. Una muestra de ello, son los castigos tan severos que eran aplicados en la región murciana, llegando incluso a lanzar al culpable al fuego que había provocado ${ }^{43}$. En los montes de Torozos, los denominados montaneros, deheseros o veladores, eran los que penaban con el pago de ciertas cuantías en metálico a quienes cortaban leña o hacían fuego en lugares prohibidos ${ }^{44}$. En Córdoba existían guardas con una gran potestad, pues podían matar a los malhechores si estos se defendían con $\operatorname{armas}^{45}$.

Los carboneros estaban obligados a la petición y utilización de una licencia específica para el desempeño de sus cometidos, normalmente aquella era emitida por los concejos. En el reino de Córdoba era esencial poseerla, estando terminantemente prohibido venderla, prestarla o utilizarla para cualquier otro fin, en caso de que lo hicieran pagarían de pena 2.000 mrs. más lo que las ordenanzas concejiles estipulaban por corte o quema ${ }^{46}$. En el reino de Jaén para principios del siglo XVI, en la ordenanza II, se estipula que ningún forastero haga carbón sin licencia de la ciudad ${ }^{47}$, de lo contrario 600 mrs. era la pena a pagar. Lo mismo ocurría en la villa de Alcalá de los Gazules, hasta que no se obtuviera la correspondiente licencia emitida por el concejo, los carboneros no podrían ejercer su profesión en ninguna zona ${ }^{48}$. En contrapartida, cuando la zona explotada no era propiedad concejil sino señorial, la situación

\footnotetext{
${ }^{41}$ Córdoba 1990b, p. 225; 1492.05.24, AGS, RGS, f. 556r-v.

${ }^{42}$ Soriano 2003, pp. 73-77.

${ }^{43}$ Martínez 1998, pp. 74-75.

${ }^{44}$ Reglero 1994, p. 241.

45 González 1975, p. 256.

${ }^{46}$ Santos 1986, p. 391.

${ }^{47}$ Porras 1993 , p. 133.

${ }^{48}$ Martín 2012, p. 1564.
} 
era diferente. El caso de Castellar de la Frontera es el que mejor representa este hecho, pues tratándose de un lugar donde predominan las espesuras de montaña y sus matorrales, el carboneo era protegido por los titulares del señorío, imponiendo el pago de un canon a los carboneros para que pudieran ejercer su actividad ${ }^{49}$. Las relaciones entre Plasencia y los señoríos de la tierra, denota igualmente las dificultades a la hora de implantar una legislación sobre tierras comunales ${ }^{50}$.

Además de la protección emitida para controlar las talas y quemas que se llevaban a cabo en los montes, también se incluía en muchas ocasiones, la regulación sobre las instalaciones siderúrgicas. En Álava desde 1332, en el condado de Foix en 1302 o en Béarn para 1354, se llevaron a cabo borradores legislativos para regular no solo la explotación del carbón y la obtención de leña, sino también las instalaciones de forjas ${ }^{51}$. En la mitad norte de la Península Ibérica, las montañas catalanas, aragonesas y navarras, han sufrido una potente ocupación al emigrar allí muchas personas entre los siglos IX y X, buscando dónde refugiarse frente a las invasiones árabes. A través de los resultados de los diagramas palinológicos y antracológicos, se conoce que esta ocupación humana en la alta montaña se mantuvo hasta el siglo XIV llevando consigo una desforestación intensa a través de actividades pastoriles, la práctica del carboneo, pero sobre todo, de la instalación de industrias metalúrgicas ${ }^{52}$. Igualmente en Valencia se han implantado medidas de cara a la conservación del monte, limitando su uso y explotación, con especial hincapié a las siderurgias. En relación con estas industrias, se podrían añadir las cecas de Barcelona documentadas por Ricardo Córdoba, donde existía una gran demanda de carbón para su funcionamiento, pues en ellas jugaba un papel muy importante para abastecer los hornos de fundición, las hornazas o los ensayos ${ }^{53}$.

En Europa, por ejemplo en territorio francés, desde los siglos IX-X ya se recogen indicios de degradación del bosque como consecuencia de la fabricación del carbón, así lo ha recogido Durand en los casos de Augery, SaintVictor, Béziers, Cassan, Couges, Laval-Basse o Castelnaudary ${ }^{54}$. En el valle de Vicdessos, también se muestra la ruptura del equilibro forestal a través de la práctica del carboneo y la instalación de siderurgias ${ }^{55}$. Bernard Davasse,

${ }^{49}$ Vilela 1999, p. 23.

${ }^{50}$ Clemente 1999, p. 445.

${ }^{51}$ Córdoba 2009, p. 408.

${ }_{52}$ Métailié 1995, pp. 406-407.

${ }^{53}$ Córdoba 2009, p. 80.

${ }^{54}$ Durand 2003, p. 183

${ }^{55}$ Verna 2002, pp. 345-353. 
al estudiar la distribución del espacio explotado en este valle pirenaico, ha conseguido trazar los límites aproximados del antiguo bosque carbonizado, demostrando que el uso intensivo del carbón produjo una crisis forestal muy fuerte entre los siglos XVI-XVII ${ }^{56}$. No obstante, las ordenanzas y legislación del valle de Vicdessos denotan un cierto interés en proteger el bosque limitando tanto la actividad carbonera como la implantación de las citadas siderúrgicas ${ }^{57}$.

En último lugar, cuando el carboneo era elaborado fuera de las ciudades, es decir, en las villas de su término municipal, la legislación aplicada era la misma que si se tratara de un pleito de usurpaciones de tierras realengas o de amojonamientos entre jurisdicciones. Por ejemplo en el alfoz cordobés, las tensiones sociales eran continuas sobre el carboneo en las villas realengas. Era frecuente que localidades como Adamuz, Pozoblanco, Hornachuelos o Belmez proporcionaran grandes cantidades de carbón, ya que su situación norteña les hacía ser ricas en esta materia prima $^{58}$, aunque también hubo una adecuada producción de carbón en la Campiña. Los pleitos que el concejo de Córdoba mantenía con estas villas estaban siempre encaminados al uso y disfrute de alguna que otra dehesa, por ejemplo para 1491 la propia ciudad prohibió a Alonso de Cea, vecino de Córdoba, realizar carbón en una dehesa que era explotada por los habitantes de Hornachuelos hasta que se solucionase el pleito existente entre ésta y la ciudad ${ }^{59}$. Igualmente Carpio Dueñas hace relación de algunos conflictos que existieron, sobre todo en la segunda mitad del siglo XV, donde los adehesamientos y usurpaciones de las "sierras bravas" situadas al norte y las disputas sobre los límites de fincas jugaron un gran pape ${ }^{60}$, tratándose en la mayoría de las ocasiones de dilatados y prolongados juicios. Así ocurre en el mencionado pleito entre Hornachuelos y Córdoba, que para 1492 se vuelve a poner de manifiesto, aclarando que era por una dehesa de la que sacan carbón ${ }^{61}$. Es decir, que un año después aún permanecía el problema sin solución alguna.

${ }^{56}$ Davasse 1993, pp. 305-314.

${ }^{57}$ Ibidem, pp. 345-346; Verna 2001.

${ }^{58}$ Córdoba 1990b, pp. 223-225.

${ }^{59}$ 1491.12.10, AGS, RGS, f. 181r-v.

${ }^{60}$ Carpio 2011, pp. 102-103.

${ }^{61}$ 1492.01.28, AGS, RGS, f. 101. 


\subsection{Tipos de carbones}

En la Baja Edad Media se han documentado distintas clases de carbón según la zona de estudio, cuya producción y tipología difiere en virtud de las masas arbóreas existentes y del uso al que se destine el carbón. A través del libro de la Montería y los Viajes de Colón, ya se detallan el jaral, madroñal, robles, encinas, entre muchos otros ${ }^{62}$. Para conocer detalladamente la diversidad de esta materia prima, son esenciales los análisis antracológicos, carpológicos y palinológicos procedentes del medio natural como demuestran los estudios de Aline Durand o Marie-Pierre Ruas ${ }^{63}$. La primera de ellas, recalca muy bien la adecuada utilidad de la antracología para los estudios del carbón, explicando que L'anthracologie étudie d'un point de vue qualitatif e quantitatif les bois carbonisés issus soit de contextes archéologiques soit de dépôts natu$r e l s^{64}$. En Francia se realizaron ya diversos estudios para la etapa medieval en los años 40 del siglo XX. Sin embargo, en otros países ha tenido menos éxito, en Italia solo existen las publicaciones de Lanfredo Castelletti y Brucato, y en España no tienen mucha cabida las investigaciones con tintes bioarqueológicos medievales ni antracológicos ${ }^{65}$. También Emilio Martín se ha hecho eco de la escasez de los datos recopilados a través del registro arqueológico ${ }^{66}$. Una posible explicación de ello, la proporciona Ricardo Izquierdo al indicar, que en la actualidad, apenas existen restos materiales que manifiesten evidencias de la huella de los carboneros, esta actividad no ha dejado ningún vestigio aparente porque normalmente el carbón de leña se realizaba en el suelo de la tierra, sin necesidad de tener que construir nada específico, a lo sumo un suelo de losas de piedra; aunque sí tuvieron que levantar chozas de barro y ramaje donde se resguardarían los carboneros mientras realizaban su trabajo ${ }^{67}$.

A pesar de esta carencia, es posible conocer muchas de las tipologías arbóreas y carboníferas a través de las menciones que hay en las fuentes documentales. La variedad más importante y consumida en la Baja Edad Media era la del carbón de encina, contando con una gran protección debido a su elevada utilización ${ }^{68}$. Actualmente está presente tanto en Extremadura y las dos Castillas como en Andalucía; por ejemplo, los encinares cordobeses de Los Pedroches son muy conocidos desde época islámica por su alta calidad, de he-

${ }^{62}$ Rackham 1995, pp. 321-322.

${ }^{63}$ Kirchner 2011, p. 371.

${ }^{64}$ Durand 2003, p. 51.

${ }^{65}$ Ibidem.

${ }^{66}$ Martín 2012, p. 1563.

${ }^{67}$ Izquierdo 2008, pp. 207-208.

${ }^{68}$ Córdoba 1990b, pp. 223-225. 
cho, los musulmanes llamaron a esta zona "Campo de las Bellotas" (Fash alBallut $)^{69}$. En Andalucía, la madera era habitual que procediese de los bosques de Cazorla, Segura, la Sierra cordobesa y los ya citados Pedroches. En los primeros, el pinar era la especie más numerosa mientras que en los otros dos -como ya se ha comentado líneas más arriba- la importancia del encinar era evidente. De cualquier manera, la utilización del pino era mucho más frecuente entre los siglos XIII-XV70 en toda la mitad sur de Castilla, concretamente de las sierras de Albarracín y las ya mencionadas Cazorla y Segura ${ }^{71}$, pues estaba menos protegido que la encina motivando que su consumo se incrementara considerablemente en el medievo. Hay constancia de la explotación maderera a través de numerosos contratos en diversas ciudades ${ }^{72}$.

Como se ha adelantado anteriormente, el árbol más importante era la encina en todo el bosque mediterráneo medieval, pues la dureza de su madera lo hacía fundamental para las actividades del mundo rural y los trabajos de carpintería ${ }^{73}$. Los encinares son muy explotados en la región andaluza para la práctica carbonera, por ejemplo en 1492 los jurados de Córdoba se quejaban de la explotación de los montes de la ciudad para la elaboración del carbón, esto desembocó en la orden de que no se destruyeran los encinares ni se cortaran otros árboles donde se podía obtener madera ${ }^{74}$. En el reino de Jaén, se especifica en la ordenanza X de 1534, que el carbón lo hagan y vendan de enzina y no de roble ${ }^{75}$. La importancia de la encina también es común en la sierra de Montsec, situada entre Lérida y Huesca, cuya explotación superó a la del roble. ${ }^{76}$. En los montes de Torozos el roble enciniego o quejigo, era la tipología más predominante, quedando la encina, enebro, moral y pino en segundo plano. Además contaban con una masa arbustiva muy variada: carrascales, estepas, jaras, retama o árgomas ${ }^{77}$. En Murcia los matorrales más utilizados eran el acebuchal, lentisco, esparto, tomillo, boj y enebro, este último muy utilizado por herreros y carboneros ${ }^{78}$.

\footnotetext{
${ }^{69}$ Rodríguez 2002, p. 194.

${ }^{70}$ López, Valle, García 1988, p. 298.

${ }^{71}$ Córdoba 2002, vol. II, p. 243.

${ }^{72}$ Córdoba 1997 , pp. 223-224.

${ }^{73}$ Córdoba 1990b, p. 224.

${ }^{74}$ Ibidem.

75 Porras 1993, p. 136.

${ }^{76}$ Sancho 2002, pp. 93-94.

${ }^{77}$ Reglero 1994, pp. 235-236.

${ }^{78}$ Martínez 1998, p. 76.
} 


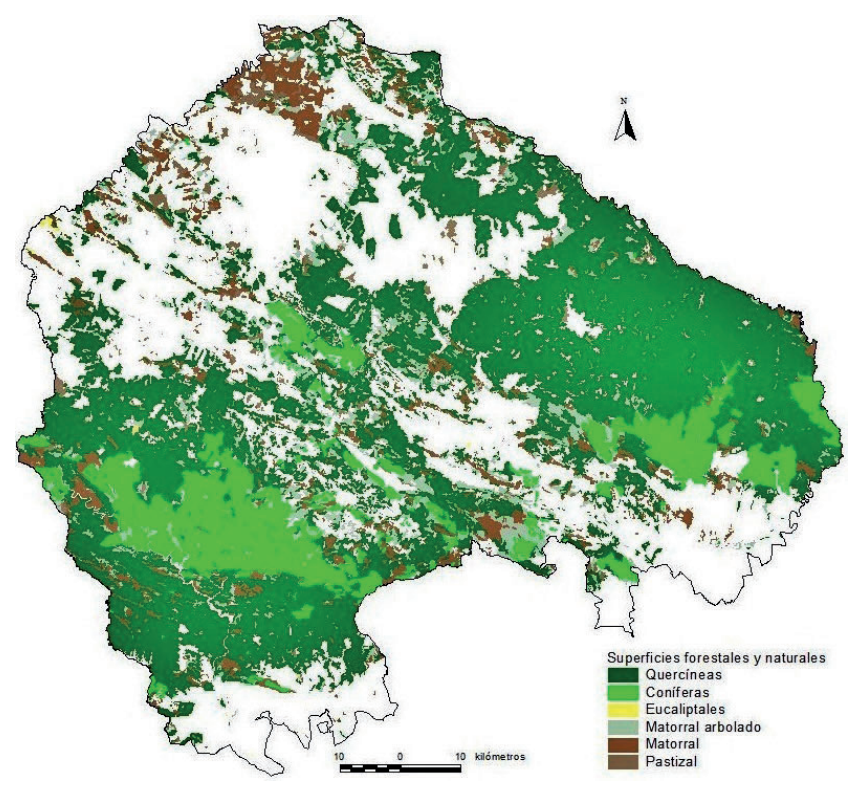

Fig. 1. Detalle de las diversas especies forestales de la Sierra de Córdoba (Luque 2012, p. 62).

En Córdoba se ha documentado la coscoja, lentisco, madroño, carrascales, jaras blancas, brezo común y brezo blanco, abulaga, matagallo, cantueso o tomillo borriquero y torvisco ${ }^{79}$. En la figura 1, que representa solamente la Sierra de la ciudad de Córdoba, puede apreciarse las diferentes masas forestales existentes, donde las quercíneas cobran mayor protagonismo. Muchas de estas especies cordobesas son semejantes a las localizadas por Aline Durand en la zona de Languedoc ${ }^{80}$. Tampoco se debe desechar el aprovechamiento del alcornocal que proporciona corcho para la saca, leña para el carboneo y bellota para la montanera. El olivar asimismo proporcionó una leña de un gran

\footnotetext{
${ }^{79}$ Cruz 2008, pp. 167-168.

${ }^{80}$ Durand 2003, pp. 185-186, 213. Por ejemplo: la coscoja (Quercus Coccifera), en LunelViel (siglos X-XII), el lentisco (Pistacia Lentiscus) en Bèziers (siglo XIII), el madroño (Arbutus unedo) en Augery (siglos IX-X), Psalmodi (siglos IV-X/VIII-XII), Saint-Santurnin (siglos X-XI), Lunel-Viel (siglos X-XII), Saint-Victor (siglo XII) y en Bèziers (siglo XIII). La encina o carrasca (Quercus ilex) en Lunel-Viel (siglos X-XII), la jara blanca (Cistus albidus) en Augery (siglos IX-X) y Saint-Victor (siglo XII), el brezo común (Calluna vulgaris) en Saint-Victor (siglo XII), y el brezo blanco (Erica arbórea) en Augery (siglos IX-X) y Lunel-Viel (siglos X-XII).
} 
poder calorífico idónea para el carbón ${ }^{81}$. En otros puntos de la Península Ibérica, más avanzada la Baja Edad Media, el pino seguía siendo más importante, como por ejemplo en Cuéllar y Sepúlveda donde se especifica en las fuentes documentales que hizieren carbón de candal o de rrama de pino, especies muy adecuadas para ello ${ }^{82}$. Durante el siglo XV en la región murciana, el pino, junto al álamo y el sauce, eran los árboles más explotados por los carboneros, teniendo muy poca importancia la encina y la coscoja ${ }^{83}$. Para la realización de los ensayos en las casas de la moneda, Juan de Arfe recomendaba encender el hornillo con carbón de pino porque gastaba menos que el de brezo ${ }^{84}$. No obstante, ante la necesidad de un alto poder calorífico, las hayas en el norte de la Península y la encina o brezo en su centro y sur, serían las especias más empleadas ${ }^{85}$.

Sea cual fuere el árbol a explotar, lo cierto es que se necesitaba muchísima madera para obtener una cantidad de carbón óptima. Según señala R. Bechmann, en la Edad Media para conseguir un kilogramo de carbón vegetal era necesario tener entre 8 y 10 kilos de madera de los bosques ${ }^{86}$; y Juan Helguera explica que entre 5 y 7 unidades de leña eran las idóneas para conseguir una de carbón vegetal ${ }^{87}$. La necesidad de tanta madera es motivada por la carbonización, que supone la pérdida de un $80 \%$ del peso de la leña ${ }^{88}$, y por tanto, las cantidades demandadas son numerosas. Evidentemente el carbón podía ser fabricado de muchas especies arbóreas aunque como el interés del hombre medieval se centraba en obtener el máximo poder térmico -el carbón supera $\operatorname{los} 1.000^{\circ} \mathrm{C}-{ }^{89}$, se utilizaron solamente algunas maderas.

En Andalucía, concretamente en Córdoba, el tipo de carbón más conocido era el denominado "carbón de humo". Por norma general, se elaboraba durante el invierno por la sencilla razón de que resultaba menos peligroso para el bosque, pues no hay que olvidar que el fuego estaba implicado en el proceso de la obtención del mismo ${ }^{90}$. También era beneficioso realizarlo en este momento del año por dos factores, primero porque era el periodo por el cual se aprovechan mejor las talas, pero a su vez -y aquí entra en juego el segundo factor- existía en esta época un mayor consumo en la sociedad bajomedieval.

${ }^{81}$ Martín 2012, p. 1563.

${ }^{82}$ Calonge 2003, p. 105.

${ }^{83}$ Martínez 1998, p. 76.

${ }^{84}$ Córdoba 2009, pp. 267-268.

${ }^{85}$ Ibidem, p. 189.

${ }^{86}$ Bechmann 1984, pp. 185-187.

${ }^{87}$ Helguera 2002, p. 382.

${ }^{88}$ Euba 2008, p. 64.

${ }^{89}$ Córdoba 2002, vol. II, p. 286.

${ }^{90}$ González 1975, vol. II, p. 332. 
Este carbón de humo solía estar fabricado de madera de encina ya que además de ser bastante dura, poseía un valioso poder calorífico. La importancia de esta tipología de carbón viene respaldada por la ordenanza del 17 de septiembre de 1480 impuesta por el propio concejo cordobés denominada Hordenança del arrendamiento del carbón de fumo, en ella se manifiestan diferentes disposiciones acerca de su venta, recolección, comercio y transporte ${ }^{91}$. Aunque la ordenanza no está completa, gracias a un traslado de la misma realizado en $1515^{92}$, se ha podido completar toda la información que falta en su libro correspondiente. Muchas de sus órdenes serán analizadas a la hora de hablar del comercio de esta materia prima, no obstante, a modo de ejemplo, se puede asegurar que se vigilaba mucho a quienes traían carbón a la ciudad; haciendo hincapié en la posesión de la obligada licencia para llevar a cabo tal actividad, en este sentido se especifica que ninguna ni algunas personas non sean osados de traer a vender carbón de humo a esta cibdad ni en otra manera syn licencia del arrendador que la dicha renta toviere arrendada ${ }^{93}$, en caso de que no tuvieran tal permiso, la pena era de perdido el dicho carbón e bestias en que lo troxieren e sea todo para el dicho arrendador, además que pague seys cientos mrs. de pena por cada carga ${ }^{94}$.

En los documentos de la época aparecen numerosos contratos de compra-venta de este tipo de carbón, señalando los lugares donde era frecuente su producción. Normalmente la zona norte de Córdoba era la más habitual para llevar a cabo todas las actividades relacionadas con la madera y el carbón, sobre todo en los montes de Cuzna, en el condado de Belalcázar, cerca de la venta del Calatraveño ${ }^{95}$. Entre 1470 y 1490 se llevaron a cabo numerosas ventas de carbón, por ejemplo en 1487 se llegaron a vender hasta 200 cargas de carbón de humo fabricadas de encina, o en 1478 donde se debían 22 cargas a Juan Ruiz Requena ${ }^{96}$. Sin duda, era la tipología más usada por los vecinos de la ciudad de Córdoba, algo probablemente aplicable para el resto de las ciudades andaluzas puesto que la encina, como ya se ha indicado, era idónea por su dureza y poder calorífico para la elaboración de este producto.

Otro tipo es el denominado "carbón de quejigo", del cual poco o nada se puede detallar puesto que la documentación es muy parca acerca del mismo. Esto nos lleva a deducir que era de peor calidad -procedía del árbol

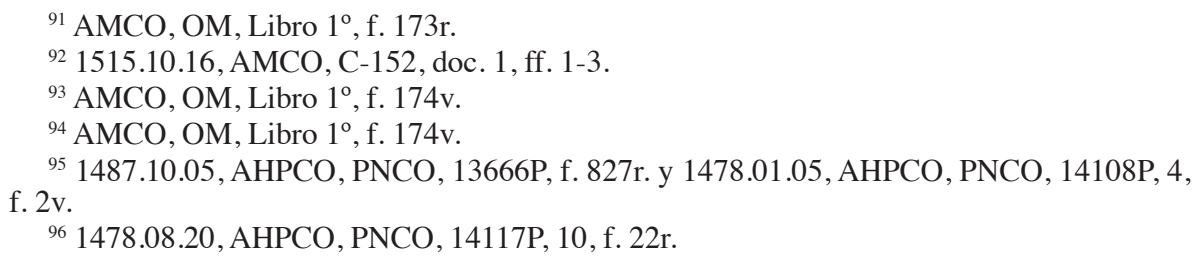


homónimo- de manera que su demanda y consumo era muy inferior al resto de las variedades de carbón existentes. Sin embargo, el tercer tipo denominado "carbón de todo monte", era algo más consumido y existe alguna que otra referencia de su fabricación. Se confeccionaba a través de la unión de todas las ramas posibles de varias especies vegetales, es decir, de todo lo que se disponía en el monte donde se iba a obtener el carbón ${ }^{97}$ ya sea pino, lentisco, desechos o ramas sueltas. En Córdoba hay una venta de 24 cargas de carbón en 1501, donde se deja vislumbrar cuál era el tipo de carbón más demandado, y por tanto de mejor calidad, puesto que se especifica que se entreguen a Alfonso García de Cea 24 cargas de carbón de humo de encina, que no sea de todo monte ${ }^{98}$. A pesar de que el precio de esta variedad de carbón era más reducido, su menor potencial térmico produjo que su consumo fuera inferior respecto a los de humo o brezo ${ }^{99}$.

La última variedad de carbón era el de brezo, que junto al carbón de humo será el que cobre mayor importancia. Era trascendental como fuente de energía térmica en la industria metalúrgica gracias a su alto poder calorífico, pues se utilizaba para la fundición de metales, para la forja de hierro en las fraguas ${ }^{100}$, cristalerías ${ }^{101}$, cerámicas o para cecas ${ }^{102}$. Su origen procede de un arbusto mediterráneo homónimo y de gran endurecimiento maderero ${ }^{103}$. Ejemplos de la utilización de este tipo de carbón se encuentran en las tres fraguas que tenía el conde de Rosellón documentadas para el siglo XIV ${ }^{104}$ o para encender el hornillo de los ensayos en las cecas, que según la recomendación de Juan Fernández del Castillo habría que usar carbón de brezo no menudo ${ }^{105}$. Igualmente en las fuentes de la época existen numerosos contratos acerca de la demanda de este carbón, así por ejemplo en 1488 Alfonso, carbonero y vecino de Las Posadas, debía un pago a Diego Díaz de Cañete, herrero, ambos acordaron pagarlos en la ciudad de Écija en carbón de brezo ${ }^{106}$; en 1490 Juan Ruiz, carbonero y vecino de Córdoba, tenía que pagar a Pablo del Pinar, vecino de Córdoba, 30 cargas de carbón de brezo a 4 costales la carga ${ }^{107}$; o en 1501 , Benito Muñoz de la Cuerda, vecino de Córdoba, vende a Juan Rodríguez,

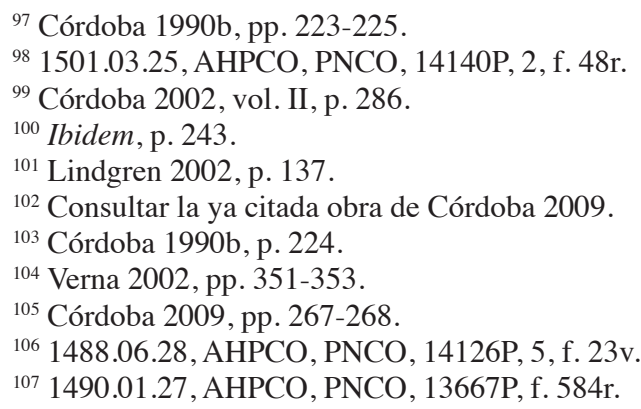

${ }^{97}$ Córdoba 1990b, pp. 223-225.

${ }_{98}$ 1501.03.25, AHPCO, PNCO, 14140P, 2, f. 48r.

${ }^{99}$ Córdoba 2002, vol. II, p. 286.

${ }^{100}$ Ibidem, p. 243.

${ }^{101}$ Lindgren 2002, p. 137.

${ }^{102}$ Consultar la ya citada obra de Córdoba 2009.

${ }^{103}$ Córdoba 1990b, p. 224.

${ }^{104}$ Verna 2002, pp. 351-353.

${ }^{105}$ Córdoba 2009, pp. 267-268.

${ }^{106}$ 1488.06.28, AHPCO, PNCO, 14126P, 5, f. 23v

${ }^{107}$ 1490.01.27, AHPCO, PNCO, 13667P, f. 584r. 
frenero, vecino de Córdoba, 3 cargas de carbón de brezo semanales durante un año ${ }^{108}$. Es frecuente encontrarse con numerosos herreros comerciando con carboneros para obtener suficiente carbón para su desempeño en la ciudad de Córdoba, así en 1465 se pagaba por cada asno de cuatro costales de carbón de brezo 24 mrs. ${ }^{109}$, mientras que llegados a 1495 se especifica que por cuatro costales cada carga a la semana se pagaba a 53 mrs., más del doble ${ }^{110}$. Esto demuestra que durante el periodo bajomedieval el carbón de brezo fue aumentando en importancia y consumo puesto que orfebres, herreros y herradores se convirtieron en clientes fijos en la utilización del mismo, provocando una mayor demanda y precio.

\subsection{Fabricación del carbón vegetal}

Hasta el momento se ha explicado las variedades de carbón existentes y la importancia que tenían en función de su utilidad. Pero cabría hacerse otras preguntas, ¿en qué consistía la práctica del carboneo? ¿Qué procedimientos habría que llevar a cabo para su elaboración? A pesar de que las fuentes documentales no indiquen mucho al respecto para el caso de Córdoba, ha sido posible reconstruir los pasos a seguir gracias a que durante el siglo XX, y en gran parte de la Península Ibérica, se ha llevado a cabo actos de carboneo hasta nuestros días, con unas fases de trabajo que no han variado demasiado a lo largo de los siglos.

La actividad se llevaba a cabo en un lugar despejado del propio monte, donde se acondicionaba limpiando y apisonándolo bien. Después, se acumulaban en un montón las diversas ramas verticalmente, de modo que se establezca una especie de chimenea que permita que el aire pueda penetrar, y por tanto, el humo tenga una salida. El diámetro podría oscilar entre 6 y $10 \mathrm{~m} .{ }^{111}$, el resultado final serían unas pilas semejantes a las recogidas en los montes Vosgos de la figura 2. En Jerez de la Frontera, también se documenta este proceso de elaboración del carbón ${ }^{112}$. Esta pila, además de contar con esa chimenea, dispondría de pequeños respiraderos dispuestos por toda ella para que se crearan corrientes de aire. En la superficie se colocarían maderas finas, helecho, hojas, musgo y tierra húmeda, mientras que por encima, se arrojaba tierra de plazas carboneras anteriores para aislar el fuego y conseguir una

\footnotetext{
108 1501.03.15, AHPCO, PNCO, 13671P, f. 131r.

109 1465.01.14, AHPCO, PNCO, 14106P, 1, f. 19v.

110 1495.03.25, AHPCO, PNCO, 14134P, 24, f. 187v.

${ }^{111}$ Euba 2008, pp. 65-66.

${ }^{112}$ Fernández 1989, pp. 39-40.
} 
combustión lenta. Una vez edificada la pila, ya se podía encender la leña siempre con cuidado de que la tierra que cubría la estructura no se cayera con el viento, de lo contrario la madera ardería y solamente se obtendrían cenizas. El transcurso de la pirólisis no debía ser muy rápido ni a temperaturas elevadas porque solamente se obtendrían gases y líquidos ${ }^{113}$.

El fuego se prendía con ayuda de otras ramas más pequeñas y brasas de una hoguera realizada cerca del montículo, de manera que cuando los troncos más cercanos a la chimenea comenzaban a arder, se taponaba el agujero de ella para ir expandiendo la combustión hacia abajo.

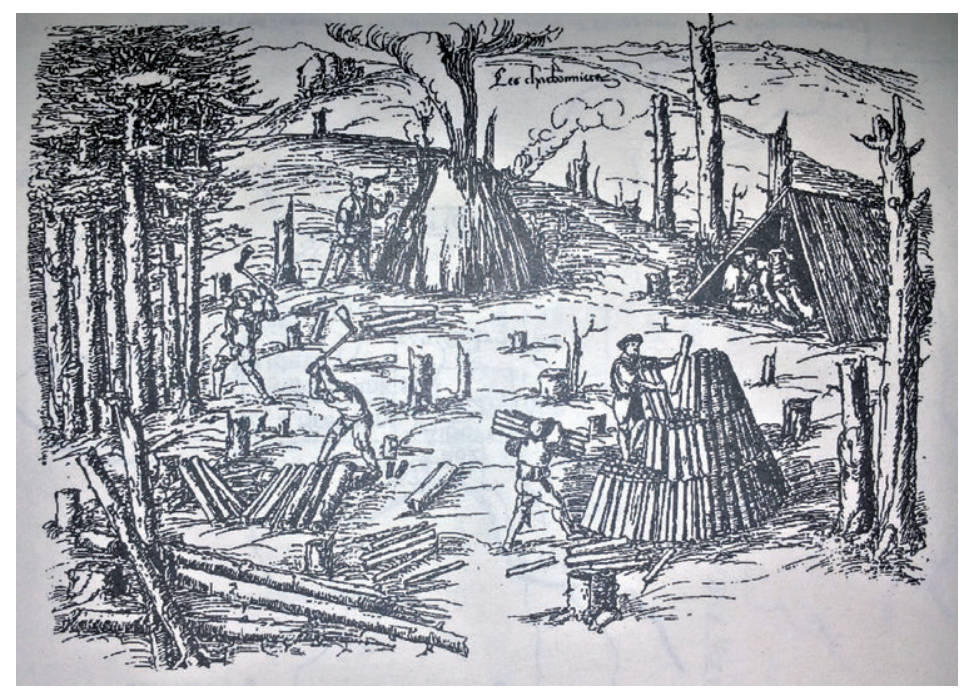

Fig. 2. Restos de árboles talados y pilas de carbón en el sistema montañoso de los Vosgos, al noreste de Francia, en la mitad del siglo XVI (Westermann 1995, p. 949).

La base de la pila de leña solía ser más influida por el viento, por ello era necesario que se ubicaran los troncos más anchos $(80 \mathrm{~cm}$ de largo por 20 $\mathrm{cm}$ de ancho aproximadamente) en dicha base y cercanos a la chimenea, pues aquí es donde la leña ardería primeramente con mayor intensidad ${ }^{114}$. Durante la carbonización, a cuanto mayor calor se someta la leña más poder calorífico se recibe del carbón, sin embargo, la cuantía de piezas de este será menor. Si los ejes fibrovasculares de una especie son densos, como es en el caso de la

${ }^{113}$ Euba 2008, pp. 65-66.

${ }^{114}$ Ibidem.

ANUARIO DE Estudios MEdievales, 46/2, julio-diciembre 2016, pp. 819-858 ISSN 0066-5061, doi:10.3989/aem.2016.46.2.08 
encina, se consigue un carbón de gran poder calorífico ${ }^{115}$. Para hacerse una idea, la energía calorífica de la madera es de $3.000 \mathrm{Kcal} / \mathrm{kg}$, mientras que la del carbón es mucho mayor, pues alcanza de 7.000-7.500 Kcal $/ \mathrm{kg}^{116}$. De hecho, la temperatura de las ascuas es de $1.200^{\circ}$ a $1.300^{\circ} \mathrm{C}^{117}$. La carbonización debe ser lenta y progresiva si se quiere obtener un buen carbón. En cambio, si se produce una carbonización rápida, el carbón obtenido no resultará de buena calidad ${ }^{118}$. Por este motivo, el carbonero solía vivir en una choza cerca de la zona donde realizaba su actividad, habitualmente en el mismo monte o bosque ${ }^{119}$. Esto le permitía estar cerca de la materia prima, pero también, permanecer junto a la producción del carbón ya que mientras se realizaba la combustión, debía vigilar el fuego y observar el color del humo para saber con exactitud cuando está terminada la cocción ${ }^{120}$. En ocasiones, pisoteaban la pila y si oían el quebrantamiento del carbón en sus pies, ya sabían que estaba listo. Cuando todo había prendido, se cubrían todos los agujeros y se dejaba ahogar el fuego, el cual podría estar de 4 a 15 días sin apagarse, dependiendo de la proporción de la carbonera ${ }^{121}$.

Al finalizar la quema, la tierra que cubría la pila se solía poner de color blanco y para extraer el carbón, la tierra se iría quitando con una pala. Allí donde aun se mantuviera parte del fuego, se volvería a cubrir con tierra. El carbón se extendía hacia los lados de la carbonera, por lo que quedaba una mancha carbonosa elíptica una vez recogido el carbón ${ }^{122}$. Del mismo modo que los agricultores tenían a su disposición herramientas de diversa tipología para su labor; los carboneros, para desarrollar adecuadamente todo el trabajo hasta el momento explicado, también contaban con pertrechos que le facilitaran su actividad. Por ejemplo, eran muy usados las hachas, cestos, palas o picos. Existían muchos otros como puede observarse en la figura 3, que desde la Edad Media hasta el siglo XX, se han venido utilizando. En las cecas estudiadas por Ricardo Córdoba, los trabajadores se servían de palas para introducir el carbón en el horno, una de hierro que sirve al fundidor para meter fuego en el horno para fundir la plata, o de madera del carbón de la fundición ${ }^{123}$.

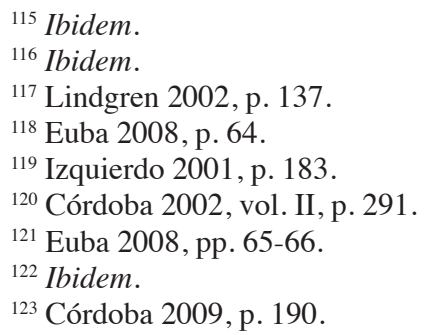




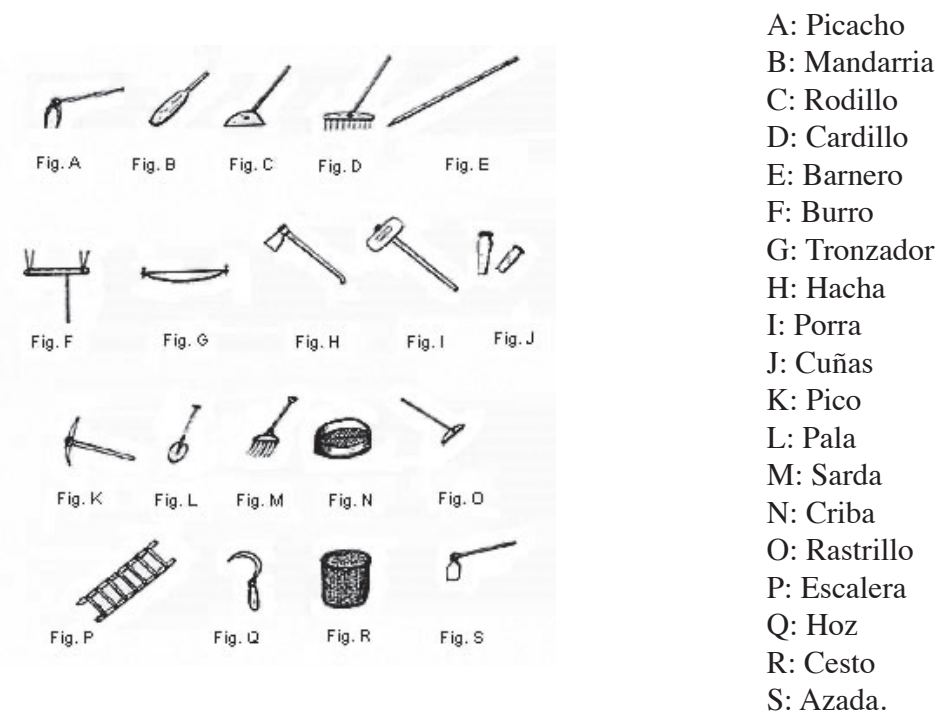

Fig. 3. Herramientas del carbonero (Polancos 1997, p. 178).

Como ya se ha indicado, el alojamiento de los carboneros se llevaba a cabo en chozas o cabañas carboneras, ubicadas normalmente en el interior de los bosques. Se sabe cómo eran construidas y de qué se componían. Solían ser edificadas a una distancia próxima de las pilas que permanecían ardiendo. Estas "viviendas" constaban de dos grandes troncos a modo de pilares, llamados puntales, que se colocaban en un ángulo variable según la altura que se quisiera obtener. En la junta de los dos puntales y apoyado en el suelo, se ubicaba el tercer tronco, denominado biga cerradera. En algunas ocasiones, si existía la oportunidad de aprovechar alguna pared de abrigo o de una pared de piedra seca, lo hacían; y entre ésta y la biga cerradera, se dejaba un vano que establecería la función de chimenea.

La otra parte, donde iría la puerta, estaba erigida con ramas. Esta puerta solía ser pequeña para evitar la penetración del aire frio durante la etapa invernal. En el interior, normalmente se separaban dos espacios con un gusín, que se trataba de un tronco que se colocaba en el suelo para separar los lugares donde se comería y dormiría ${ }^{124}$. La figura 4 recoge muy bien cómo quedaría la morfología de la cabaña de los carboneros, además de los utensilios de los

\footnotetext{
${ }^{124}$ Ibidem .
} 
que se servían para cocinar y alimentarse durante sus duras estancias en el monte. Aunque estos enseres son de principios del siglo XX, algunos de ellos serían muy parecidos a los del hombre medieval como el botijo, el cuchillo o la cuchara.

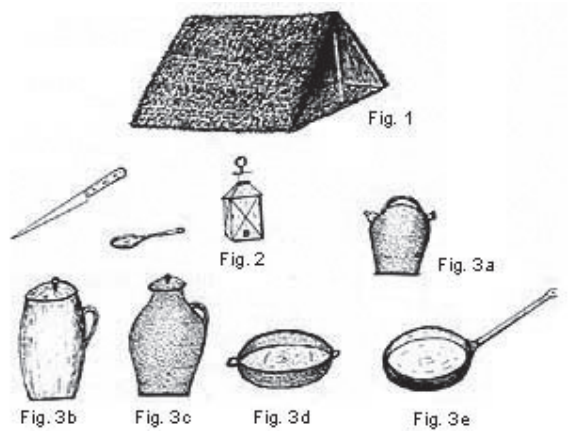

1: Cabaña de carbonero

2: Farol

3: Utensilios:

a) Barrilla o botijo

b) Puchero de porcelana (hierro esmaltado)

c) Puchero de barro

d) Cazuela de barro

e) Sartén.

Fig. 4. Cabaña e instrumentos de cocina de los carboneros (Polancos 1997, p. 176).

Los lugares donde se efectuaba el carboneo, por norma general, eran los montes de las propias ciudades o en los términos de las villas de su alfoz. En la mayoría de las ocasiones, como ya se manifestó, será el propio concejo quien imponga las zonas donde se permitía llevar a cabo la práctica del carboneo. En el sur peninsular será predominantemente en las sierras donde se produzca esta actividad, ya se han citado ejemplos directos como la sierra de Aroche, de Aracena donde destacaban "Las Atarazanas", en Córdoba su propia Sierra (Figura 5) o Los Pedroches. Sin embargo, las fuentes documentales del siglo $\mathrm{XV}$, también recogen ciertos pagos donde se practicaba el carboneo en territorio cordobés, como Las Berrocosillas, Navaherrado ${ }^{125}$ o los ya citados montes de Cuzna.

Del mismo modo, en la documentación de la época, existen numerosas referencias que muestran los lugares donde los vecinos de cada municipio fabricaban carbón, para después transportarlo a la ciudad cordobesa. De toda la provincia, los pueblos que exportaban más carbón eran Hornachuelos y Cabra. En el primer caso, ya se comentó el conflicto que mantuvo con la propia ciudad acerca de la obtención de carbón de una dehesa; aunque también exis-

${ }^{125}$ Córdoba 1990b, p. 225. 
ten otras noticias que demuestran la continua llegada de este producto al comercio cordobés ${ }^{126}$. En cuanto a Cabra, además de madera y caza, es frecuente encontrar en la documentación información sobre compras y ventas de carbón procedente de su monte. En 1500 se pusieron a la venta 400 cargas de carbón de encina de $\mathrm{Cabra}^{127}$, y en 1493 Alfonso Rodríguez recibe varias cargas de carbón de humo del monte de la villa de Cabra a precio de un real de plata la carga ${ }^{128}$.

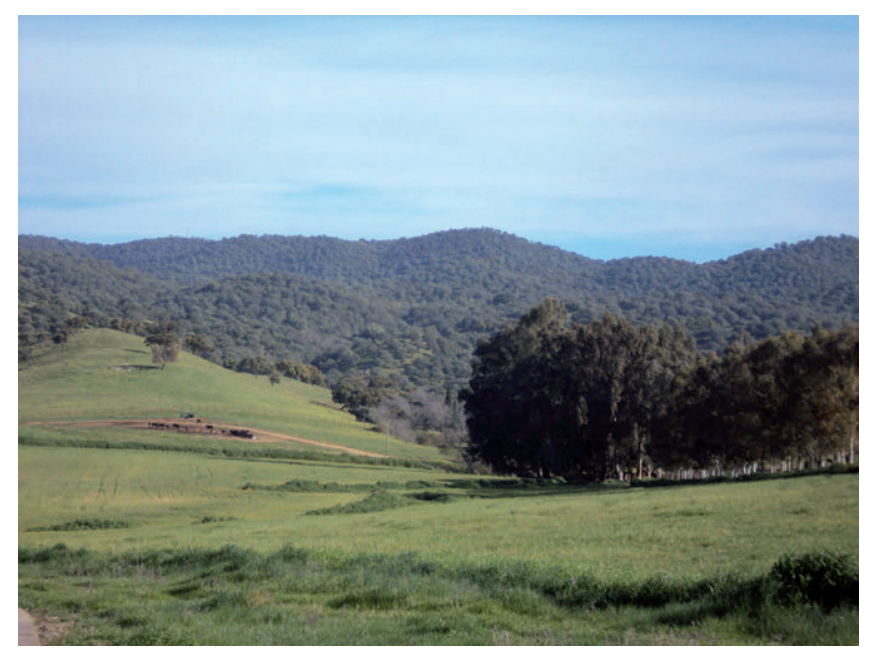

Fig. 5. Paisaje del piedemonte de la Sierra de Córdoba próximo a la barriada de Villarrubia (R.J. Díaz).

Obviamente no eran las únicas villas que surtían de carbón a la ciudad, ya han sido mencionadas Adamuz, Belmez o Pozoblanco. En las fuentes documentales aparece, por ejemplo, Fuente Ovejuna, concretamente el monte de los Ojuelos donde en 1494 se obtuvieron 200 cargas de carbón de humo ${ }^{129}$; igualmente en las proximidades de El Villar se producía carbón de brezo, cerca del campo de Ayuso, en esta ocasión consistía en 50 cargas ${ }^{130}$. Para el resto del sur peninsular la sierra norte sevillana será la que ocupe la mayor parte de

\footnotetext{
126 1491.12.27, AHPCO, PNCO, 14129P, 15, f. 33r.

127 1500.03.31, AHPCO, PNCO, 13672P, f. 129v.

${ }_{128} 1493.02 .04$, AHPCO, PNCO, 14131P, 1, f. 35r.

${ }^{129} 1494.12 .10$, AHPCO, PNCO, 13670P, f. 1144v.

${ }^{130}$ 1498.11.13, AHPCO, PNCO, 14137P, 27, f. 32v.
} 
la explotación carbonífera, a través de villas como Constantina y Carmona; del mismo modo en Jaén, la sierra de Cazorla o de Segura serán las predominantes, al igual que en Huelva las ya citadas Aroche y Aracena o en Cádiz la sierra de Grazalema.

\subsection{El transporte}

Otro aspecto interesante de la práctica del carboneo es su transporte. En la Península Ibérica, el carbón era un producto muy valorado y con un gran peso en la sociedad, un ejemplo de ello fue el sur de Aragón, donde el carbón estaba inmerso en el tráfico comercial jugando un papel social muy importante ${ }^{131}$. La venta de éste producto generaba problemas muy variopintos, sobre todo en relación al precio, a sus vendedores o a los almacenamientos ilegales en el interior de la ciudad. Sirviéndonos de las ordenanzas de 1480 del concejo cordobés, se analizará la normativa existente para el trasporte del carbón en esta ciudad y su posterior comercio, que puede ser aplicada al resto de las ciudades.

El transporte era realizado tanto por vía terrestre como marítima ${ }^{132}$. En el primero de los casos, el carbón se transportaba desde el monte a la ciudad por medio de bestias de carga como asnos, mulos o recuas cargados de cuatro costales cada uno y embalados en vasijas, los oficios relacionados con ello son los acemileros, arrieros o recueros ${ }^{133}$. En la documentación de la época existen muchas referencias acerca de la utilización de estas bestias para la guerra de Granada, donde los concejos contrataban a los antedichos transportistas para abastecer de ciertos productos a las tropas que participaban en la contienda. Así se sabe que transportaban grano, verduras, frutas, pero también objetos manufacturados como carbón, leña, pieles de animales salvajes, entre otros ${ }^{134}$. En el continente europeo, concretamente en el reino de Francia, el carbón se trasladaba por tierra desde Fenouilledes y Corbières, de Saint-Paul-de-Fenouillet y de Maury, y más al norte, Cubieres, Soulatgé, Cucugnan y Padern. Las entregas se realizan en pequeñas cantidades, por lo general uno o dos saumades, siendo seis saumades el máximo alcanzable ${ }^{135}$. En Jerez de la Frontera, se tiene constancia del transporte del carbón en 1467 a través de las quejas del concejo, pues debían de pagar $10 \mathrm{mrs}$. por cada carretada ${ }^{136}$.

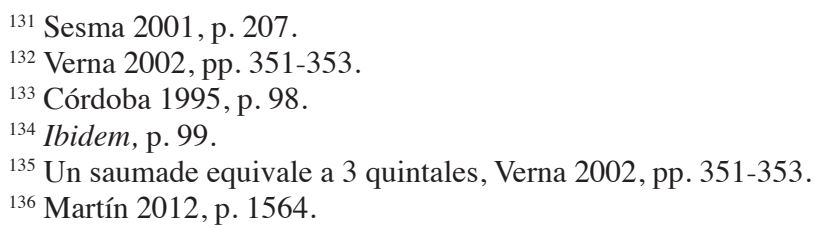


Ejemplos directos del transporte de carbón los encontramos cerca de la venta del Calatraveño para 1487, donde ya se indicó la venta de 200 cargas de carbón de humo de encina a precio de $31 \mathrm{mrs}$. la carga; se especifica que se recogerá toda la mercancía en la dehesa del Tarragoso de Cuzna, en un plazo de tres meses; durante este tiempo el comprador debe recogerlo con sus bestias y transportarlo a Córdoba ${ }^{137}$. Del mismo modo Juan Palma, carbonero, fue requerido por Juan de Mesa, lugarteniente del alguacil mayor de Córdoba, para disponer de cinco bestias para llevar pan a Málaga, explica que no dispone de los animales demandados por hallarse en el monte transportando carbón, incluso dos testigos lo confirman ${ }^{138}$. Todas las ciudades reflejaban en sus ordenanzas un reglamento a seguir, en el caso cordobés se pide a estos arrieros que cada carga sea de tres costales, y para la falda o seras el costal sea equivalente al marco de Córdoba; si no se cumpliera esta norma, el carbón sería destinado al brasero de la ciudad más el pago de $100 \mathrm{mrs}$. de pena para el arrendador si encuentran al arriero o acemilero vendiendo la mercancía ${ }^{139}$.

El utillaje utilizado en el caso cordobés, y probablemente para muchas más zonas peninsulares, era muy sencillo. Se recurría al uso de las cinchas y albardas de la caballería puesto que permitían mantener bien atadas las mercancías depositadas sobre los lomos del animal. En la documentación bajomedieval, aparecen espuertas, esportones y esportillos para desplazar de unos lugares a otros los productos. No obstante, serán las denominadas seras o serones, las utilizadas frecuentemente para la fruta y el carbón. Se trataban de espuertas de un tamaño mayor, en ocasiones sin asas. En Córdoba se alquilaban los serones por $2 \mathrm{mrs}$. diarios ${ }^{140}$. En la Sierra del reino de Jaén, según la ordenanza IV, se plasma la utilización de seras de marca, para evitar los fraudes y engaños ${ }^{141}$. Se impuso que todos los carboneros vendan el carbón con dos seras, una para asnos, donde deben caber tres arrobas y media, siendo un total entre las dos de siete arrobas, que era la carga anual que la ciudad tenía ${ }^{142}$. En las cecas documentadas por Ricardo Córdoba, el carbón era transportado hasta la fundición con cestos o canastas ${ }^{143}$. En cuanto a la vía fluvial como medio de transporte, el río Guadalquivir proporcionó madera a Sevilla y Córdoba desde las sierras de Cazorla y Segura ${ }^{144}$. Los denominados "bar-

${ }^{137}$ 1487.10.05, AHPCO, PNCO, 13666P, f. 827r.

${ }^{138} 1503.01 .03$, AHPCO, PNCO, 14142P, 18, f. 5v.

${ }^{139}$ AMCO, OM, Libro $1^{\circ}$, f. $174 \mathrm{v}$.

${ }^{140}$ Córdoba, Hernández 2003, pp. 160-161.

${ }^{141}$ Porras 1993, p. 134.

142 Ibidem.

${ }^{143}$ Córdoba 2009, p. 190.

${ }^{144}$ Carmona 2011, pp. 194-195.

ANUARIO DE Estudios MEDIEVALES, 46/2, julio-diciembre 2016, pp. 819-858 ISSN 0066-5061, doi:10.3989/aem.2016.46.2.08 
queros de Córdoba" eran los encargados de llevar las mercancías (incluido el carbón) entre Sevilla y Córdoba desde el siglo XIII. Formaban un grupo de 40 transportistas como máximo para el siglo $\mathrm{XV}^{145}$. En Córdoba existió el mesón de los Barqueros, en el barrio de Santa María para inicios del siglo XVI; teniendo alusión probablemente a los barqueros que pernoctaban allí.

La circulación de este producto y su entrada en el entramado urbano estaba también muy controlado por las ordenanzas del concejo cordobés, de hecho, se estipula con claridad para 1480 cuáles eran las puertas por las que debían entrar las cargas de carbón: la de Plasencia, la del Rincón y la del Puente ${ }^{146}$. Si no se cumple esta obligación y tampoco se tiene licencia para ello, se le condenaría al culpable a recibir veinte azotes públicamente. Del mismo modo, se exigía a aquellas personas que trasladaban con licencia el carbón de los montes a la ciudad, de no descargar los costales fuera de la ciudad de Córdoba en una legua a la redonda -entre 4 y $7 \mathrm{~km}$ aproximadamente-; de lo contrario debían pagar el carbón con el quatro tanto e más las bestias en que lo troxeren para el arrendador que faga dello lo que quisyere ${ }^{147}$. Incluso si los transportistas se oponían a esta penalización, el arrendador podía llevar al alguacil a aplicar lo dictado por las ordenanzas, especificándose que lo lieue a casa del alcalde mayor para que lo vea sumariamente e que determine lo que fuere justicia ${ }^{148}$.

Otra de las normas impuestas -que ya se aludió precedentemente- es la necesidad de una licencia emitida por el arrendador para transportar el producto hasta la ciudad con la finalidad de venderlo. En caso de no poseerla, la pena ascendía hasta los 600 mrs. por cada carga que llevase, además de perder las bestias y la cantidad de carbón que transportara en ellas ${ }^{149}$. Esto permitía controlar de algún modo las ventas ilegales de carbón así como los fraudes, que en muchas ocasiones, estaban a la orden del día en los mercados. Muy relacionada con esta condición, estaba aquella otra que regula la fabricación del carbón en la ciudad de Córdoba, pues de nuevo se pide como requisito indispensable una licencia del arrendador. Sin embargo, aquí la pena es mucho mayor especificándose que:

so pena que por la primera vez que lo fysiere que pague dos mill mrs. de pena, e por la segunda vez, cinco mill mrs.; esto porque sy asy oviese a pasar syn premia, el dicho arrendador non podría aver el dicho carbón para pagar a los señores Córdoua ${ }^{150}$.

${ }^{145}$ Córdoba 1997, p. 220.

${ }^{146}$ AMCO, OM, Libro $1^{\circ}$, f. $174 \mathrm{v}$.

${ }^{147}$ AMCO, OM, Libro $1^{\circ}$, f. $175 \mathrm{v}$.

${ }_{148}$ AMCO, OM, Libro $1^{\circ}$, f. 175v.

149 1515.10.16, AMCO, C-152, doc. 1, f. 1r.

${ }^{150}$ 1515.10.16, AMCO, C-152, doc. 1, f. 2v. 
$\mathrm{El}$ arrendador cuando proporcionaba la oportuna licencia a cualquier vecino especificaba cuáles eran las zonas que estaban permitidas para la práctica del carboneo, cabe recordar que los concejos tenían costumbre de dar prioridad a unas áreas más que otras con la finalidad de conceder descanso al monte y no limitar los recursos que se aprovechaban. Para 1480 el arrendador, con el mandamiento emitido por el concejo, permitía hacer carbón en todos los montes realengos del concejo de Córdoba, exceptuando Los Pedroches y las dehesas concejiles ${ }^{151}$. Esto también ocurría en otras zonas de la Península Ibérica, por ejemplo en Toledo, donde el carbón procedía de sus montes denominados Puerto Carbonero y arroyo de Carboneros, lugares elegidos por el concejo toledano para que sus vecinos hicieran carbón ${ }^{152}$. Las ordenanzas de Carbonero el Mayor (Segovia), desde 1409 tenían un estricto control sobre la fabricación de carbón, puesto que al gozar de un buen comercio de carbón de pino y encina, tuvieron que establecer serias medidas para proteger el monte denominado El Reguenal de Temeroso ${ }^{153}$.

Como se expresará a continuación, a pesar de las duras medidas, el concejo cordobés era tolerante respecto aquellas personas que introducían carbón en la ciudad para consumo propio, aunque no poseyeran licencia. Probablemente se permitía porque el producto carbonífero no estaba destinado a la venta, por tanto lo único que se les exigía a esas personas era efectuar el pago correspondiente al arrendador para obtener el derecho de traer dicho carbón a la ciudad, la pena de no cumplir la orden suponía la pérdida del producto y las bestias ${ }^{154}$.

\subsection{Comercialización}

Respecto al comercio del carbón, lo normal era que los mismos carboneros vendiesen el producto a orfebres, herreros y mercaderes. En los contratos de compra-venta aparecen numerosos carboneros negociando con herreros para proporcionarles carbón semanalmente, y ese precio variaba considerablemente al alza. Así el precio del carbón de brezo de 1465 a 1495 se encareció más del doble ${ }^{155}$, mientras que el de humo para 1478 valía en torno

${ }^{151}$ AMCO, OM, Libro $1^{\circ}$, f. 175 r.

${ }^{152}$ Molénat, 1997, pp. 273-274.

${ }^{153}$ Ramos 2003, p. 236.

${ }^{154}$ AMCO, OM, Libro $1^{\circ}$, f. 174v.

${ }^{155} \mathrm{Si}$ comparamos, por ejemplo, estos dos contratos, se demuestra la subida del precio del carbón de brezo. La carga pasa de $24 \mathrm{mrs}$. a 70 mrs., 1465.01.14, AHPCO, PNCO, 14106P, 1, f. 19v. y 1482.11.05, AHPCO, PNCO, 13666P, f. 87r. 
a 18 mrs. cada carga, sin embargo nueve años después, la carga se tasaba en 31 mrs. Posiblemente se deba a dos factores, por una parte a la importante demanda que tuviera, y por otro, a los cambios de valor de la moneda durante la segunda mitad del siglo XV en diferentes años. En este sentido, el concejo cordobés también aplicaba un precio estándar para las cargas de carbón que entrasen en la ciudad. El 11 de enero de 1492, existían quejas por parte de los vecinos al estar obligados a pagar un impuesto de $15 \mathrm{mrs}$. por cada carga de carbón que introdujesen en Córdoba. El cabildo ante las numerosas protestas y observando el agravio que causaba, decidió imponer esa cuantía a todos aquellos que metieran carbón a la ciudad para venderlo. Por otra parte, los individuos que acarreasen sus cargas carboníferas para solamente uso doméstico, no debían pagar nada:

que se non lleue ni pida ni demande del carbón que los vecinos e moradores metiesen para las nesçesydades e gasto de sus casas que non fuere para vender (...) lo pueda meter libremente syn pagar $^{156}$.

En relación a esta normativa, también se dictó que aquellas personas que trajesen carbón a la ciudad con la finalidad de venderlo, debían pagar de entrada $5 \mathrm{mrs}$. por ciento para la primera venta, para las restantes no se exigía ningún pago adicional ${ }^{157}$. Así quien quisiera vender este producto, la primera vez que entrase en la ciudad pagaría un total de $20 \mathrm{mrs}$. y 15 mrs. para el resto de las ocasiones. El propio concejo de Córdoba, estipulaba el precio de las cargas de carbón, indicando la cantidad a pagar por parte de aquellas personas que traían carbón a la ciudad con licencia del arrendador, para 1480 cada carga menor eran $12 \mathrm{mrs}$. mientras que la mayor sería el doble, es decir, $24 \mathrm{mrs} .{ }^{158}$. Entre los contratos hallados para Córdoba, el carbón de humo era muy demandado; para 1485 Gonzalo López debía pagar a Juan Cazorla, 14 cargas de carbón de humo, también Pedro de Gijón adeudaba al maestro Juan 100 cargas de carbón de humo especificando que debe de fabricarse en el monte de la Haza del Mariscal ${ }^{159}$. Por citar otro ejemplo, aparece en 1497 una deuda de Gonzalo Paneque, al que se le obliga que la primera semana lleve una carga de carbón y otras 10 cargas hasta que cumpla los $2.600 \mathrm{mrs} .{ }^{160}$. Uno de los contratos más sustan-

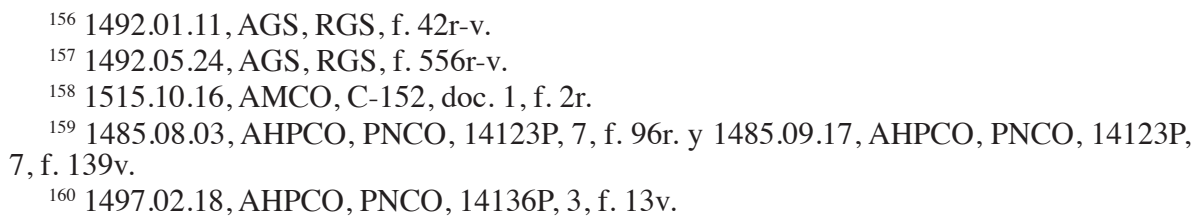


ciosos en cuanto al carbón de humo se refiere, se recoge para el año 1500 donde se acuerda la venta de 400 cargas de carbón de encina, realizando un reparto de 200 cargas para la ciudad de Córdoba, mientras que el resto de la mercancía debía ser recogida por el propio comprador, en este caso, en el monte de la villa de Cabra ${ }^{161}$.

En términos generales, se acostumbraba llevar a cabo la venta del carbón en los meses de octubre-diciembre o enero-marzo, dejando el resto del año para la fabricación del mismo ${ }^{162}$. En la zona de Piedrahita la carga de tres costales de a fanega de medio costal, de sierra de Miranda y del Colmenar y desde finales de octubre a finales de marzo, tenía un precio de $21 \mathrm{mrs}$., la misma carga de finales de marzo a finales de octubre era más económica, unos 18 mrs.. La carga de costales de Zapardiel de la Ribera de finales de octubre a fines de marzo era de $15 \mathrm{mrs}$. mientras de finales de marzo a finales de octubre se reducía a $12 \mathrm{mrs}{ }^{163}$. El precio era más o menos elevado dependiendo si la fabricación del carbón se realizaba en el interior del término de la villa de Piedrahita, o por el contrario, procedía de fuera.

Los fraudes y engaños estaban a la orden del día en el comercio, por ello los concejos aplicaban ordenanzas para regular los pesos, precios, calidades o medidas de los recipientes. En Jaén, las ordenanzas II, IV, VI, VII, XI y XII, se encargan de estos pormenores ${ }^{164}$. Por ejemplo, en la sexta, se recoge que se producían muchos engaños y fraudes. Los carboneros lo vendían a un precio muy elevado por no dar buenas cargas ni aver seras de marca, en las seras no viene lo que deve venir (...) y no dan tanto carbón a los compradores como devian ${ }^{165}$. En Córdoba, los herreros no son olvidados por las autoridades pertinentes ni tampoco el resto de los vecinos de la ciudad; pues en las ordenanzas de 1435 se estipula que todos ellos no sean osados de fazer ni fagan almazén en sus casas nin fuera dellas, nin pongan depósyto ninguno ni algunos carbón de breço para lo revender a los dichos ferreros $^{166}$, la multa era de $100 \mathrm{mrs}$. Esta prohibición ayuda a descubrir tres aspectos muy interesantes, por un lado que esta ley se mantuvo a lo largo de la Baja Edad Media, al menos para el caso cordobés, ya que en las ordenanzas de 1480 y 1495 siguieron aplicando el castigo pertinente sobre aquellas personas que tuviesen almacenes o depósitos para el carbón de brezo. Así para 1480 se vuelve a dejar claro que ninguna ni algunas presonas non

161 1500.03.31, AHPCO, PNCO, 13672P, f. 129v.

${ }^{162}$ Córdoba 1990b, pp. 223-225.

${ }^{163}$ Santos 1986, p. 404.

${ }^{164}$ Estrella, Asla 2010, p. 198.

${ }^{165}$ Porras 1993, p. 134.

${ }^{166}$ González 1975, p. 280.

ANUARIO de Estudios Medievales, 46/2, julio-diciembre 2016, pp. 819-858 ISSN 0066-5061, doi:10.3989/aem.2016.46.2.08 
puedan fazer almazén nin vender en sus casas carbón por menudo, so pena que lo aya perdido, saluo el arrendador o a quien él diere licencia ${ }^{167}$. Existen referencias acerca de quién tenía esa licencia, por ejemplo, Gonzalo de Escobar, candelero, era arrendador de la renta de caza, leña y carbón de la ciudad de Córdoba en 1487 arrendando a Juan Muñoz, todos los almacenes de carbón que se vendieran por libras en la propia ciudad ${ }^{168}$. En segundo lugar, se puede dilucidar que el comercio del carbón no estaba exento de estafas y fraudes, ya que tanto vendedores como compradores llevaban a cabo todas las artimañas posibles para obtener el mayor beneficio económico. Y en tercer lugar, se demuestra una vez más que el carbón de brezo sigue siendo junto al carbón de humo la tipología carbonífera más importante de la ciudad de Córdoba, al menos así se refleja en las ordenanzas de 1435, 1480 y 1495 , donde se menciona y restringe constantemente esta tipología carbonífera.

Los ingresos que proporcionaba el carbón eran importantes según la ciudad en cuestión, en Piedrahita a mediados del siglo XV, tanto la leña como el carbón tenían precios más elevados en otoño e invierno por motivo de la alta demanda. No obstante, el precio del carbón dependía del origen de procedencia del mismo, es decir, no era igual el fabricado fuera de la jurisdicción de la villa que de su propia tierra ${ }^{169}$. En la periferia noroccidental de los montes de Calatrava, el carbón tenía un buen mercado en Ciudad Real. Un gran porcentaje de la población se dedicaba al carboneo, a veces en combinación con otros oficios ${ }^{170}$. En la zona de Aragón, los registros de las aduanas indican el gran volumen de carbón que se destinaba al exterior, entre los años de 1444 y 1445, en Arcos de las Salinas eran 18.000 kg, en La Hoya de la Carrasca unos $15.000 \mathrm{~kg}$, o en Almansa 5.000 kg ${ }^{171}$.

El reino de Sevilla incluso disponía de una renta denominada "montaracía", que era un conjunto de ingresos procedentes de la autorización emanada del propio concejo para fabricar carbón en los montes concejiles ${ }^{172}$. Sin embargo, ya en el siglo XV acabó desapareciendo. En 1484, Carmona obtuvo 1.100 mrs. de esta renta ${ }^{173}$. Por su parte, la villa de Constantina, además de proveer de espacios concretos a sus habitantes para hacer sus carboneras, se vio en la obligación de intervenir con algunos derechos sobre estas explota-

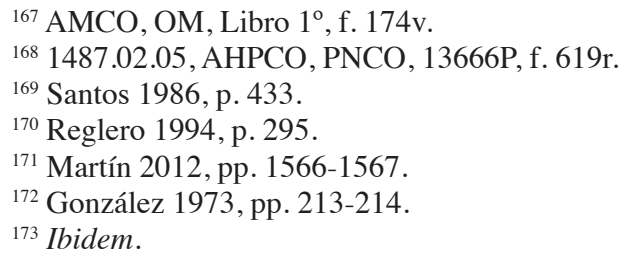


ciones, gracias a esto para 1435 los ingresos procedentes del carbón fueron destinados a reparar el castillo de la villa ${ }^{174}$. También existieron las montaracías en otras zonas del sur, como en Cádiz, concretamente en Jerez. El concejo cordobés recaudaba sus beneficios aplicando una serie de impuestos conjuntamente para el carbón y la tala de árboles como se demuestra en 1497, donde al corregidor de esta ciudad se le pide que haga cumplir los impuestos a aquellas personas que deben pagarlos por vender y almacenar carbón en la ciudad $^{175}$. Dentro del territorio onubense, áreas como la sierra de Aroche y Aracena, el carboneo jugaba un papel mucho menos importante porque era el menos practicado ${ }^{176}$.

En último lugar, es conveniente señalar que de la elaboración del carboneo se consigue otro beneficio económico requerido en las ciudades medievales, como es la ceniza. Cuando se quema la madera y se produce la combustión se obtienen unas cenizas muy ricas en potasa, fosfatos y otros productos que, mezclados con agua, se convierten de gran utilidad ${ }^{177}$. En la vida doméstica las cenizas se usaban para fabricar lejía con la que se lavaban las ropas, y en el ámbito industrial, para el vidrio, jabón o curtidos. Las más utilizadas eran las barrillas, procedentes de la sosa al quemar las plantas, solía realizarse en los meses de verano en hornos con paredes arcillosas fabricados en el terreno ${ }^{178}$. Las almonas de las ciudades como Cáceres o Córdoba, demandaban constantemente estas cenizas para la fabricación de jabón ${ }^{179}$, por ello existen abundantes contratos de arrendadores de almonas que compran cenizas procedentes, por ejemplo, de la Sierra de Córdoba. Así en 1484 Antón Martín de Cañete vende a Pedro Fernández 600 fanegas de ceniza de lentisco, con un precio de $40 \mathrm{mrs}$. cada fanega en la almona de Juan de Sosa, o en 1502 dos vecinos de la villa de Fernán Núñez, Cristóbal Ruiz y Nicolás, vendieron dos cargas de ceniza a Juan Cañete por otros $40 \mathrm{mrs} .{ }^{180}$. En Jaén también fabricaban ceniza constantemente, incluso existen varios pleitos entre villas

\footnotetext{
${ }^{174}$ Carmona 2011, p. 196.

175 1497.10.14, AGS, RGS, f. 48r-v.

${ }^{176}$ Pérez-Embid 1988, pp. 260-262.

${ }^{177}$ Cabrera 2002, pp. 265-266.

${ }^{178}$ Córdoba 2002, vol. II, p. 293.

${ }^{179}$ En las Actas Capitulares de la ciudad de Córdoba, aparecen numerosas referencias sobre "el ensay del jabón". Por ejemplo en las sesiones de 1493.03.08, 1493.03.20, 1493.03.29, 1493.07.24, 1495.09.23, 1501.01.11, 1501.05.12 y 1501.09.13 (consultar AMCO, LAC 2, LAC 3 y LAC 9). Siempre se indican los mismos ingredientes y cantidades: 1 arroba de aceite, 2 libras de aceite, 1 fanega de ceniza, 1 fanega de cal y 1 carga de leña.

180 1484.02.13, AHPCO, PNCO, 14122P, 9, f. 28r. En este caso Pedro de Angulo, diputado de la ciudad, tomó juramento de Cristóbal Ruiz y Nicolás, vecinos de Fernán Núñez, y juraron que hoy vendieron dos cargas de ceniza a Juan de Cañete, a $40 \mathrm{mrs}$. la fanega, 1502.05.10, AHPCO, PNCO, 14141P, 8, f. 15r.
} 
como Úbeda y Baeza, sobre el uso de los términos del río Guadalimar para hacer ceniza ${ }^{181}$.

En algunos contratos se especifica ciertos detalles de la elaboración de ceniza, por ejemplo que conforme se vaya fabricando se guarde en una choza para evitar que se reste calidad o se pierda al completo el producto ${ }^{182}$. La ciudad de Córdoba también tuvo la necesidad de proteger los montes respecto a la producción de ceniza ya que el fuego era necesario para tal fin. Las ordenanzas cordobesas de 1435 restringen que se realizase en Los Pedroches ${ }^{183}$ así como que se hagan quemas para conseguir ceniza; bajo penalización de $100 \mathrm{mrs}$. y que le quiten los animales de carga que llevasen, además de pagar 12 mrs. para el mayordomo. Solo se permitía hacer fuegos para ceniza en la mata de San Nicolás, concretamente en el Acebuchar, y en los intervalos temporales del año que el propio concejo dispusiera ${ }^{184}$.

\section{CONCLUSIONES}

Queda de manifiesto que, desde la época de predominio de al-Andalus, el hombre ha tenido una preocupación por el paisaje que le rodea, ya sea para defenderse o aprovecharse de él. Después de la victoria cristiana en 1212, la explotación del monte medieval comenzó a recrudecerse notablemente junto con el aumento de la demografía. Como consecuencia de estos hechos tan significativos, los concejos peninsulares iniciaron un corpus legislativo hacia la protección y conservación del bosque, en otras palabras, otorgaron una interpretación diferente al medio natural, convirtiéndose inconscientemente en partidarios de una corriente ecologista. Muestra de ello, son las diversas penalizaciones que se han enumerado para diferentes regiones, pagos en metálico, la implantación de guardas forestales, incluso las condenas físicas a los reos que cortaban o quemaban sin el permiso concejil. Gracias a estas y otras medidas, pudieron mantener el aprovechamiento de los numerosos recursos que ofrecía el monte medieval. Entre ellos, está bien claro que el carbón vegetal era muy importante, no solo en la corona de Castilla o de Aragón, sino en todo el continente europeo. Por tanto, esa seguridad del monte beneficiaba tanto a ganaderos, carboneros, cazadores, herreros, leñadores o colmeneros como

\footnotetext{
${ }^{181}$ Córdoba 2002, vol. II, p. 293.

${ }^{182}$ Se recoge que "hecha la ceniza y metida en choza se perdiere por no enviar con tiempo el dicho jurado a por ella, que sea obligado a pagarles toda la ceniza que así se perdiere", 1470.04.06, AHPCO, PNCO, 13665P, f. 4r.

${ }^{183}$ González 1975, p. 257.

${ }^{184}$ Ibidem, p. 263.
} 
a los propios concejos de las ciudades ya que era un recurso económico de primera magnitud ${ }^{185}$.

A través de los documentos bajomedievales, se ha logrado conocer los diferentes tipos de carbón que existían, variables según las especies arbóreas y arbustivas que se utilizaban así como sus fines. No obstante, los carbones de humo, de brezo, de "todo monte" y de quejigo localizados en el reino de Córdoba, fueron producidos prácticamente en toda la Península Ibérica. Los abundantes contratos de compra-venta plasmados a lo largo de estas páginas, han dejado entrever los pormenores del transporte desde las carboneras hasta la ciudad, para después llevar a cabo su correspondiente venta. Ha sido posible conocer los diferentes utillajes que se utilizaban, los precios y el tamaño de las mercancías en función de la zona que sea objeto de estudio, así como los fraudes y engaños que realizaban. También se ha documentado la gran utilidad que poseía el carbón, muy utilizado para cristalerías, ferrerías, cecas, joyerías, braseros, entre otros muchos usos; además de la ceniza que dejaba, la cual tenía una gran cabida en el mercado.

Finalmente, aunque es interesante el conocimiento de las cabañas de carboneros y sus utensilios tanto para desarrollar su oficio como para alimentarse y vivir allí durante los meses de trabajo, sería muy beneficioso impulsar la tipología de estudios desarrollada en la zona de Barcelona, Francia y el resto de Europa. Basta con ojear los trabajos de Aline Durand, Bernard Davasse, Lanfredo Castelletti, Marie-Pierre Ruas, Vincent Clément, Itxaso Euba, Jean-Paul Métailié, Jean-Jacques Dubois, entre muchos otros. El registro arqueológico sobre la práctica del carboneo en la Baja Edad Media, podría proporcionar muchísima información con ayuda de los análisis palinológicos, antracológicos, bioarqueológicos y biogeográficos. Como bien cita Dubois y defiende Rameau, es necesaria la combinación de las variables naturalistas e históricas para llevar a cabo una arqueología de paisaje completa ${ }^{186}$. Así las salidas al campo complementarían la información de la documentación archivística. Con la biogeografía histórica podría incluso alcanzarse cotas de información que no se recogen en la cartografía o la toponimia ${ }^{187}$. Ya aludió Izquierdo Benito la necesidad de localizar los restos materiales de la práctica del carboneo.

En definitiva, este estudio ayuda a forjarse una idea de la importancia del monte para el hombre y las sociedades bajomedievales, gracias al análisis de la explotación carbonífera y todo lo relacionado con ella (transporte, comercio y fabricación), que se llevaba a cabo durante este periodo histórico en

${ }^{185}$ González 1975, vol. II, p. 333.

${ }^{186}$ Dubois 1995, p. 259; Rameau 1993, pp. 241-272.

${ }^{187}$ Dubois 1995, p. 264. 
el reino de Córdoba. Está claro que conocer y percibir los diferentes usos que se otorgaba al territorio a fines de la Edad Media, es importante, y más aún, si son actividades y formas de vida, que en la actualidad, paulatinamente están desapareciendo, como es la del carboneo y los carboneros.

\section{BIBLIOGRAFÍA CITADA}

Almagro Vidal, Clara (2012), Frontera, medio ambiente y organización del espacio: de la cuenca del Guadiana a Sierra Morena (Edad Media), Granada, Universidad de Granada (tesis doctoral).

Bechmann, Roland (1984), Des arbres er des hommes. La fôret au Moyen Age, París, Flammarion.

Cabrera Muñoz, Emilio (2002), El bosque, el monte y su aprovechamiento en la España del Sur durante la Baja Edad Media, en Pérez-Embid Wamba, Francisco Javier (ed.), La Andalucía Medieval: actas de las I Jornadas de Historia Rural y Medio Ambiente, Huelva, Universidad de Huelva, pp. 249-272.

Calonge Cano, Guillermo (2003), Implicaciones biogeográficas de las ordenanzas medievales de las comunidades de Cuéllar y Sepúlveda sobre un monte de pinos como elemento esencial de la vegetación autóctona, en Guerra Velasco, Juan Carlos; Manuel Valdés, Carlos; Sierra de Grado, Rosario; Peso Taranco, Carlos del; Fernández Manso, Antonio Alfonso; Martínez Fernández, Luis Carlos (eds.), Actas de la II reunión sobre Historia Forestal, Valladolid, Universidad de Valladolid, pp. 103-108.

Carmona Ruiz, María Antonia (2011), El aprovechamiento de los espacios incultos en la Andalucía Medieval: el caso de la Sierra Norte de Sevilla, en Martín, Emilio (coord.), El paisaje rural en Andalucía Occidental durante los siglos bajomedievales: actas de las I Jornadas Internacionales sobre paisajes rurales en época medieval, Cádiz, Universidad de Cádiz, pp. 193-208.

Carpio Dueñas, Juan Bautista (2011), Evolución del paisaje y aprovechamientos económicos en la falda de la sierra cordobesa (siglos XIII-XV), "Meridies" 9, pp. 87-121.

Córdoba de la Llave, Ricardo (1990a), La candelería, un oficio medieval. Apicultura y trabajo de la cera en la Córdoba del siglo XV, en Actas del I Congreso de Jóvenes Historiadores y Geógrafos, Madrid, Universidad Complutense de Madrid, vol. I, pp. 777-790.

Córdoba de la Llave, Ricardo (1990b), La industria medieval de Córdoba, Córdoba, Obra cultural de la Caja Provincial de Ahorros de Córdoba. 
Córdoba de la Llave, Ricardo (1995), Comunicaciones, transportes y albergues en el reino de Córdoba a fines de la Edad Media, "Historia. Instituciones. Documentos" 22, pp. 87-118.

Córdoba de la Llave, Ricardo (1997), Navegación y transporte fluvial en la Península Ibérica a fines de la Edad Media, en Criado de Val, Manuel (coord.), Actas del III Congreso Internacional de Caminería Hispánica, Madrid, Aache Ediciones, pp. 215-233.

Córdoba de la Llave, Ricardo (2002), Las técnicas pre-industriales, en García Ballester, Luis (coord.), Historia de la ciencia y de la técnica en la corona de Castilla. II: Edad Media, Valladolid, Junta de Castilla y León, pp. 221-432.

Córdoba de la Llave, Ricardo (2009), Ciencia y técnica monetarias en la Castilla bajomedieval, Madrid, Fundación Juanelo Turriano.

Córdoba de la Llave, Ricardo; Hernández Íñigo, Pilar (2003), El utillaje de los transportes en la Andalucía del descubrimiento, "Historia. Instituciones. Documentos" 30, pp. 159-180.

Clemente Ramos, Julián (1999), Explotación del bosque y paisaje natural en la tierra de Plasencia (1350-1550), en Actas del IX Congreso de Historia Agraria, Bilbao, Universidad del País Vasco, pp. 441-454.

Clemente Ramos, Julián (ed.) (2001), El medio natural en la España Medieval: actas del I Congreso sobre Ecohistoria e Historia Medieval, Cáceres, Universidad de Extremadura.

Clément, Vincent (1993), Frontière, reconquête et mutation des paysages végétaux entre Duero et Sistème Central du XI au milieu du XV siècle, "Mélanges de la Casa de Velázquez" 29/1,pp. 87-126 (monográfico "Antiquité et Moyen-Age").

Clément, Vincent (1997), La frontera y el bosque en el medievo: nuevos planteamientos para una problemática antigua, en Segura Artero, Pedro (coord.), Actas del Congreso la Frontera Oriental Nazarí como Subjeto Histórico (s. XIII-XVI), Lorca-Vera, 22 a 24 de noviembre de 1994, Almería, Instituto de estudios almerienses, pp. 325-334.

Clément, Vincent (2003), El concepto de transición forestal y su interés para la comprensión de los bosques actuales. El ejemplo de la Tierra de Pinares segoviana (s. XI-XX), en Sebastián Amarilla, José Antonio; Uriarte Ayo, Rafael (coords.), Historia y economía del bosque en la Europa del Sur (siglos XVIII-XIX), Zaragoza, Universidad de Zaragoza, pp. 39-68.

Cruz Gutiérrez, José (2008), Los piconeros cordobeses, Córdoba, La Posada. Davasse, Bernard (1993), Les espaces forestiers de la haute vallée de Vicdessos (Pyrénées ariégeoises): analyse écohistorique et étude des charbonnières, en Géhu, Jean-Marie (ed.), Phytodynamique et

ANUARIO DE Estudios MEdievales, 46/2, julio-diciembre 2016, pp. 819-858

ISSN 0066-5061, doi:10.3989/aem.2016.46.2.08 
Biogéographie historique des fôrets, Berlín - Stuttgart, J. Cramer, pp. 306-314 (Colloques Phytosociologiques; 20).

Dubois, Jean-Jacques (1995), Espaces et paysages forestiers du Nord-Ouest de la France du XIIIe au XVIIIe siécles: l'apport de la biogéographie historique, en Cavaciocchi, Simonetta (ed.), L'uomo e la foresta, secc. XIII-XVIII, Florencia, Instituto Internacional de Historia Económica "F. Datini", pp. 253-296 (Atti della 27 settimana di studi).

Durand, Aline (2003), Les paysages médiévaux du Languedoc (XIe-XIIe siécles), Toulouse, Presses Universitaires du Mirail.

Estrella, Jorge; Asla, Alberto (2010), El aprovisionamiento de leña en las ciudades de la Baja Edad Media hispana, Estudios de Historia de Espa$\tilde{n} a$, "Estudios de Historia de España" 12/1, pp. 185-200.

Euba Rementeria, Itxaso (2008), Análisis antracológico de estructuras altimontanas en el valle de la Vansa-Sierra del Cadí (Alt Urgell) y en el valle del Madriu (Andorra): explotación de recursos forestales del Neolítico a época moderna, Tarragona, Universitat Rovira i Virgili, departament d'Història i Geografía (tesis doctoral).

Fernández Galiano, Emilio (1989), Guía de los Montes de Propios de Jerez de la Frontera, Jerez de la Frontera, Ayuntamiento.

Furió i Diego, Antoni (2001), La domesticación del medio natural. Agricultura, ecología y economía en el país Vasco en la Baja Edad Media, en Clemente Ramos, Julián (ed.), El medio natural en la España Medieval: actas del I Congreso sobre Ecohistoria e Historia Medieval, Cáceres, Universidad de Extremadura, pp. 57-103.

González de Molina, Manuel; Martínez Alier, Juan (eds.) (1993), Historia y Ecología, Madrid, Marcial Pons (Ayer; 11).

González González, Julio (1975), Repoblación de Castilla la Nueva, vol. II, Madrid, Universidad Complutense de Madrid.

González Jiménez, Manuel (1973), El concejo de Carmona a fines de la Edad Media (1464-1523), Sevilla, Diputación Provincial de Sevilla.

González Jiménez, Manuel (1975), Ordenanzas del concejo de Córdoba (1435), "Historia. Instituciones. Documentos" 2, pp. 191-315.

Guerra Velasco Juan Carlos, Manuel Valdés, Carlos; Sierra de Grado, Rosario; Peso Taranco, Carlos del; Fernández Manso, Antonio Alfonso; Martínez Fernández, Luis Carlos (eds.) (2003), Actas de la II reunión sobre Historia Forestal, Valladolid, Universidad de Valladolid.

Helguera Quijada, Juan (2002), Los problemas energéticos de la industria española a finales del siglo XVIII: Entre el agotamiento de las energías tradicionales y el fracaso de las nuevas fuentes de energía, en Cavacciochi, Simonetta (ed.), L'uomo e la foresta, secc. XIII-XVIII, 
Florencia, Instituto Internacional de Historia Económica "F. Datini”, pp. 381-406 (Atti della 34 settimana di studi).

Hidalgo Nuchera, Patricio y Padilla Álvarez, Francisco (1998), Las ordenanzas de colmeneros del concejo de Córdoba: (siglos XV-XVIII), Córdoba, Posada.

Izquierdo Benito, Ricardo (2001), El aprovechamiento del medio natural en el reino de Toledo durante los siglos bajomedievales, en Clemente Ramos, Julián (ed.), El medio natural en la España Medieval: actas del I Congreso sobre Ecohistoria e Historia Medieval, Cáceres, Universidad de Extremadura, pp. 163-193.

Izquierdo Benito, Ricardo (2008), La cultura material en la Edad Media. Perspectiva desde la arqueología, Granada, Universidad de Granada.

Kirchner, Helena (2011), Arqueología del paisaje y arqueología de los espacios de cultivo en las sociedades hispánicas medievales, "Imago Temporis. Medium Aevum" 5, pp. 363-389.

Lindgren, Uta (2002), Energie et Technologie au Moyen-Age, en Cavacciochi, Simonetta (ed.), Economia e energia, secc.XIII-XVIII, Florencia, Instituto Internacional de Historia Económica "F. Datini", pp. 132-153 (Atti della 34 settimana di studi).

López Ontiveros, Antonio, Valle Buenestado, Bartolomé; García Verdugo, Francisco (1988), Caza y paisaje geográfico en las Sierras Béticas según el Libro de la Montería, en Cabrera Muñoz, Emilio (coord.), Andalucía entre Oriente y Occidente (1236-1492): V Coloquio Internacional de Historia Medieval Andaluza, Córdoba, Diputación de Córdoba, pp. 281-308.

López Ontiveros, Antonio (1989), Desforestación y plan forestal andaluz, "Revista de Estudios Regionales" 25, pp. 39-50.

Luque Revuelto, Ricardo Manuel (2012), Poblamiento y hábitat rural en la Sierra de Córdoba, Córdoba, Universidad de Córdoba (tesis doctoral).

Malpica Cuello, Antonio (2001), El medio natural y el poblamiento medieval del reino de Granada, en Clemente Ramos, Julián (ed.), El medio natural en la España Medieval: actas del I Congreso sobre Ecohistoria e Historia Medieval, Cáceres, Universidad de Extremadura, pp. 141-162.

Manuel Valdés, Carlos (ed.) (1999), Actas de la I reunión sobre Historia Forestal, Madrid, Sociedad Española de Ciencias Forestales.

Martínez Carrillo, María de los Llanos (1998), Explotación y protección del medio vegetal en la Baja Edad Media murciana, "Miscelánea medieval murciana" 1-2, pp. 71-82.

Martín Gutiérrez, Emilio (coord.) (2011), El paisaje natural en Andalucía Occidental durante los siglos bajomedievales: actas de las I Jornadas

ANUARIO DE Estudios MEdievales, 46/2, julio-diciembre 2016, pp. 819-858

ISSN 0066-5061, doi:10.3989/aem.2016.46.2.08 
Internacionales sobre paisajes rurales en época medieval, Cádiz, Universidad de Cádiz.

Martín Gutiérrez, Emilio (2012), En los Bosques andaluces. Los carboneros a finales de la Edad Media, en Mundos medievales: espacios, sociedades y poder: homenaje al profesor José Ángel García de Cortázar y Ruiz de Aguirre, Santander, Universidad de Cantabria, vol. II, pp. 1561-1572.

Métailié, Jean-Paul (1995), La fôret du village et la fôret charbonnée. La mise en place des paysages forestiers dans la chaîne pyrénéenne, en Cavaciocchi, Simonetta (ed.), L’uomo e la foresta, secc. XIII-XVIII, Florencia, Instituto Internacional de Historia Económica "F. Datini”, pp. 397-422 (Atti della 27 settimana di studi).

Molénat, Jean Pierre (1997), Campagnes et Monts de Tolède du XIIe au XVe siècle, Madrid, Casa de Velázquez.

Pérez-Embid Wamba, Francisco Javier (1988), La estructura de la producción agraria en las sierras de Aroche y Aracena a fines de la Edad Media, en Cabrera Muñoz, Emilio (coord.), Andalucía entre Oriente y Occidente (1236-1492): V Coloquio Internacional de Historia Medieval Andaluza, Córdoba, Diputación de Córdoba, pp. 233-270.

Pérez-Embid Wamba, Francisco Javier (2001), Desforestación y reforestación en Sierra Morena occidental (siglos XIII-XVI), en Clemente Ramos, Julián (ed.), El medio natural en la España Medieval: actas del I Congreso sobre Ecohistoria e Historia Medieval, Cáceres, Universidad de Extremadura, pp. 451-473.

Pérez-Embid Wamba, Francisco Javier (ed.) (2002), La Andalucía Medieval: actas de las I Jornadas de Historia Rural y Medio Ambiente, Huelva, Universidad de Huelva.

Pino García, José Luis del (1996), Caza y cazadores en la Castilla bajomedieval, "Meridies" 3, pp. 89-118.

Polancos Aretxabala, Miguel (1997), La vida del carbonero y proceso para la obtención del carbón vegetal, "Zainak. Cuadernos de AntropologíaEtnografía” 14, pp. 173-187.

Porras Arboleda, Pedro Andrés (1993), Ordenanzas de la Muy Noble, Famosa y Muy Leal Ciudad de Jaén, Guarda y Defendimiento de los Reinos de Castilla, Granada, Universidad de Granada.

Rackham, Oliver (1995), Forest History of Countries without Much Forest. Questions of Conservation and Savanna, en Cavaciocchi, Simonetta (ed.), L'uomo e la foresta, secc. XIII-XVIII, Florencia, Instituto Internacional de Historia Económica “F. Datini”, pp. 297-326 (Atti della 27 settimana di studi).

Rameau, Jean-Claude (1993), Les grands modéles de dynamique linéaire observables en France, en Géhu, Jean-Marie (ed.), Phytodynamique 
et Biogéographie historique des fôrest, Berlín - Stuttgart, J. Cramer, pp. 241-272 (Colloques Phytosociologiques; 20).

Ramos Santos, José María (2003), Las transformaciones de los montes de encinas y quejigos en las llanuras de la cuenca del Duero durante la Edad Moderna, en Guerra Velasco, Juan Carlos; Manuel Valdés, Carlos; Sierra de Grado, Rosario; Peso Taranco, Carlos del; Fernández Manso, Antonio Alfonso; Martínez Fernández, Luis Carlos (eds.), Actas de la II reunión sobre Historia Forestal, Valladolid, Universidad de Valladolid, pp. 233-241.

Reglero de la Fuente, Carlos Manuel (1994), Espacio y poder en la Castilla medieval. Los montes de Torozos (siglos X-XIV), Valladolid, Diputación Provincial de Valladolid.

Rodríguez Molina, José (1978), El Reino de Jaén en la Baja Edad Media, Granada, Universidad de Granada.

Rodríguez Molina, José (2002), Monte y cultivo en el Alto y Medio Guadalquivir, en Pérez-Embid Wamba, Francisco Javier (ed.), La Andalucía Medieval: actas de las I Jornadas de Historia Rural y Medio Ambiente, Huelva, Universidad de Huelva, pp. 159-208.

Sancho i Planas, Marta (2002), Explotación de recursos naturales y producción de hierro en la Alta Edad Media: el ejemplo del valle de Sant Esteve de la Sarga (Pallars Jussá- Lérida), "Meridies" 5-6, pp. 87-106.

Santos Canalejo, Elisa Carolina de (1986), La historia medieval de Plasencia y su entorno geo-histórico: la Sierra de Béjar y la Sierra de Gredos, Cáceres, Diputación de Cáceres.

Segura Graiño, Cristina (2009), ¿Historia ecológica en la Edad Media? Fuentes y bases teóricas, "Imago Temporis. Medium Aevum" 3, pp. 369-389.

Sesma Muñoz, José Ángel (2001), El bosque y su explotación económica para el mercado en el sur de Aragón en la Baja Edad Media, en Clemente Ramos, Julián (ed.), El medio natural en la España Medieval: actas del I Congreso sobre Ecohistoria e Historia Medieval, Cáceres, Universidad de Extremadura, pp. 195-215.

Soriano Martí, Javier (2003), La documentación medieval y la sostenibilidad de los aprovechamientos forestales mediterráneos, en Guerra Velasco, Juan Carlos; Manuel Valdés, Carlos; Sierra de Grado, Rosario; Peso Taranco, Carlos del; Fernández Manso, Antonio Alfonso; Martínez Fernández, Luis Carlos (eds.), Actas de la II reunión sobre Historia Forestal, Valladolid, Universidad de Valladolid, pp. 73-78.

Verna, Catherine (2001), Le temps des moulines: fer, technique et société dans les Pyrénées centrales, XIIIe-XVIe siècles, París, Publications de la Sorbonne.

ANUARIO de Estudios Medievales, 46/2, julio-diciembre 2016, pp. 819-858 ISSN 0066-5061, doi:10.3989/aem.2016.46.2.08 
Verna, Catherine (2002), Fer, bois, houille: forge hydraulique et gestion des combustibles (Pyrénées-Languedoc, XIVe siècle), en Cavacciochi, Simonetta (ed.), Economia e energia, secc. XIII-XVIII, Florencia, Istituto Internazionale di Storia Economica "F. Datini”, pp. 341-456 (Atti della 34 settimana di studi).

Vilela Gallego, Pilar (1999), Ordenanzas de Castellar de la Frontera (15101631), Cádiz, Instituto de Estudios Campogibraltareños.

Westermann, Ekkehard (1995), Central European Forestry and Mining Industries in the Early Modern Period. An Analysis of Conflicts and Research Problems, en Cavaciocchi, Simonetta (ed.), L'uomo e la foresta, secc. XIII-XVIII, Florencia, Istituto Internazionale di Storia Economica “F. Datini”, pp. 927-953 (Atti della 27 settimana di studi).

Fecha de recepción del artículo: diciembre 2013

Fecha de aceptación y versión final: mayo 2015 